University of Nebraska - Lincoln

DigitalCommons@University of Nebraska - Lincoln

Biological Systems Engineering: Papers and

Publications

Biological Systems Engineering

\title{
$5-2015$
}

\section{Use of Precisely Sculptured Thin Film (STF) Substrates with Generalized Ellipsometry to Determine Spatial Distribution of Adsorbed Fibronectin to Nanostructured Columnar Topographies and Effect on Cell Adhesion}

\author{
Tadas Kasputis \\ University of Nebraska-Lincoln, tkasputi@umich.edu \\ Alex Pieper \\ University of Nebraska-Lincoln \\ Keith Brian Rodenhausen \\ University of Nebraska-Lincoln \\ Daniel Schmidt \\ University of Nebraska-Lincoln and National University of Singapore \\ Follow this and additional works at: https://digitalcommons.unl.edu/biosysengfacpub \\ Derek Sekora \\ ivenstityf \\ Nanoscience and Nanotechnology Commons, and the Other Civil and Environmental Engineering \\ Commons \\ See next page for additional authors
}

Kasputis, Tadas; Pieper, Alex; Rodenhausen, Keith Brian; Schmidt, Daniel; Sekora, Derek; Rice, Charles; Schubert, Eva; Schubert, Mathias; and Pannier, Angela K., "Use of Precisely Sculptured Thin Film (STF) Substrates with Generalized Ellipsometry to Determine Spatial Distribution of Adsorbed Fibronectin to Nanostructured Columnar Topographies and Effect on Cell Adhesion" (2015). Biological Systems Engineering: Papers and Publications. 679.

https://digitalcommons.unl.edu/biosysengfacpub/679

This Article is brought to you for free and open access by the Biological Systems Engineering at DigitalCommons@University of Nebraska - Lincoln. It has been accepted for inclusion in Biological Systems Engineering: Papers and Publications by an authorized administrator of DigitalCommons@University of Nebraska Lincoln. 


\section{Authors}

Tadas Kasputis, Alex Pieper, Keith Brian Rodenhausen, Daniel Schmidt, Derek Sekora, Charles Rice, Eva Schubert, Mathias Schubert, and Angela K. Pannier 
Published in Acta Biomaterialia 18 (May 2015), pp. 88-99; doi: 10.1016/j.actbio.2015.02.016 Copyright (c) 2015 Acta Materialia, Inc. Published by Elsevier Ltd. Used by permission. Submitted October 21, 2014; revised January 9, 2015; accepted February 13, 2015; published online February 21, 2015.

Supplemental material follows the references.

\title{
Use of Precisely Sculptured Thin Film (STF) Substrates with Generalized Ellipsometry to Determine Spatial Distribution of Adsorbed Fibronectin to Nanostructured Columnar Topographies and Effect on Cell Adhesion
}

\author{
Tadas Kasputis, ${ }^{1,5}$ Alex Pieper, ${ }^{1,5}$ Keith Brian Rodenhausen, ${ }^{2,5}$ \\ Daniel Schmidt, 2,3,5 Derek Sekora, ${ }^{2,5}$ Charles Rice, ${ }^{2,5}$ Eva Schubert, 2,5 \\ Mathias Schubert, ${ }^{2,4,5}$ and Angela K. Pannier ${ }^{1,4,5,6}$
}

1. Department of Biological Systems Engineering, University of Nebraska-Lincoln, Lincoln, Nebraska, USA

2. Department of Electrical Engineering, University of Nebraska-Lincoln, Lincoln, Nebraska, USA

3. Singapore Synchotron Light Source, National University of Singapore, Singapore

4. Nebraska Center for Materials and Nanoscience, University of Nebraska-Lincoln, Lincoln, Nebraska, USA

5. Center for Nanohybrid Functional Materials, University of Nebraska-Lincoln, Lincoln, Nebraska, USA

6. Mary and Dick Holland Regenerative Medicine Program, University of Nebraska Medical Center, Omaha, Nebraska, USA

Corresponding author - Angela K. Pannier, 231 L. W. Chase Hall, Lincoln, NE 68583-0726, USA; telephone 402-4720896 (office), 402-472-0899 (lab); fax 402-472-6338; email apannier2@unl.edu 


\begin{abstract}

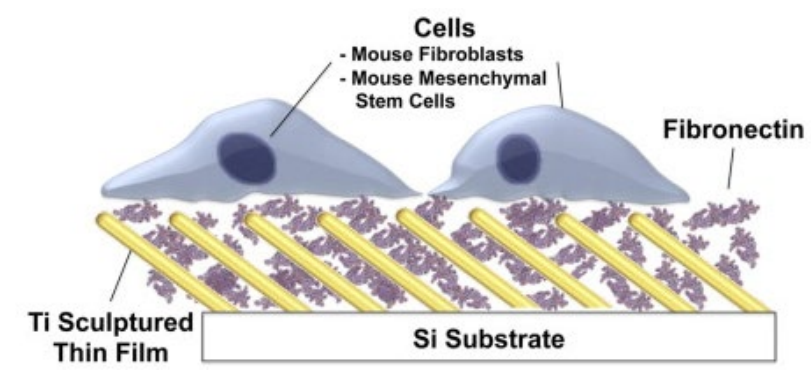

Sculptured thin film (STF) substrates consist of nanocolumns with precise orientation, intercolumnar spacing, and optical anisotropy, which can be used as model biomaterial substrates to study the effect of homogenous nanotopographies on the three-dimensional distribution of adsorbed proteins. Generalized ellipsometry was used to discriminate between the distributions of adsorbed FN either on top of or within the intercolumnar void spaces of STFs, afforded by the optical properties of these precisely crafted substrates. Generalized ellipsometry indicated that STFs with vertical nanocolumns enhanced total FN adsorption two-fold relative to flat control substrates and the FN adsorption studies demonstrate different STF characteristics influence the degree of FN immobilization both on top and within intercolumnar spaces, with increasing spacing and surface area enhancing total protein adsorption. Mouse fibroblasts or mouse mesenchymal stem cells were subsequently cultured on STFs, to investigate the effect of highly ordered and defined nanotopographies on cell adhesion, spreading, and proliferation. All STF nanotopographies investigated in the absence of adsorbed FN were found to significantly enhance cell adhesion relative to flat substrates; and the addition of FN to STFs was found to have cell-dependent effects on enhancing cell-material interactions. Furthermore, the amount of FN adsorbed to the STFs did not correlate with comparative enhancements of cell-material interactions, suggesting that nanotopography predominantly contributes to the biocompatibility of homogenous nanocolumnar surfaces. This is the first study to correlate precisely defined nanostructured features with protein distribution and cell-nanomaterial interactions. STFs demonstrate immense potential as biomaterial surfaces for applications in tissue engineering, drug delivery, and biosensing.

Keywords: nanotopography, surface analysis, protein adsorption, biocompatibility, cell adhesion

\title{
1. Introduction
}

Topographical substrate influences on protein adsorption and adhered cell behavior have been the subject of many investigations beginning with microstructured substrate features, which have been shown to influence protein adsorption, cell attachment, spreading, migration, patterning, proliferation, morphology, and differentiation, presumably by spatially confining adsorbed proteins, cell-secreted extracellular matrix proteins and cells themselves [1-5]. Recently, materials with nanotopographical features (1-100 nm feature size) have been investigated as cell culture substrates for biosensing, tissue engineering scaffolds, and therapeutic drug delivery systems; and to gain more understanding regarding nanoscale protein adsorption and cell-material interactions [6-9].

Nanoscale substrate topography and nanoroughness have been shown to influence similar cell behaviors as with microscale rough substrates, such as cell adhesion, spreading, morphology, proliferation, and differentiation in a variety of cell lines [9-15], however 
most of these investigations have been conducted on nanostructured topographies with disordered or irregular features. For example, indiscriminate distributions of carbon nanotubes have been shown to support protein adsorption [16] and the culture of neural cells $[16,17]$ and osteoblasts $[18,19]$. Furthermore, nanorough surfaces prepared by sputtering $\mathrm{TiO}_{2}$ and $\mathrm{SiO}_{2}$ have demonstrated improvements in platelet and endothelial cell adhesion with respect to unmodified surfaces, which was found to be attributed to both the surface chemistry and nanotopography [20]. However, since these studies evaluated cell behaviors on disordered nanotopographies, the work presented here aims to investigate protein adsorption and cell behaviors using highly ordered coherent arrays of nanostructured columnar substrates with varying nanocolumn spacing/orientation and to determine the precise three-dimensional distribution of proteins either on top of or within nanocolumnar features.

Advances in substrate fabrication strategies have enabled the engineering of biomaterial surfaces possessing distinct microstructured and nanostructured topographical features [21-24]. Substrates consisting of a homogenous nanocolumnar array, referred to as sculptured thin films (STFs), can be produced by many different methods including, but not limited to, lithography, sputtering, as well as physical and chemical vapor deposition [2527]. However, STFs are most commonly fabricated by employing glancing angle deposition (GLAD), a physical vapor deposition technique facilitated by electron beam evaporation. This approach results in STFs that possess intricate and complex architectures ranging in size from the sub-nano to micro-scales depending on the vapor flux angle, substrate rotation, and deposition duration, which affect the column height, slanting angle, and spacing $[25,28-30]$. The GLAD technique is applicable to a wide range of materials including metals, semiconductors, insulators, and polymers, resulting in a wide array of nanostructures with significantly different structural, mechanical, electrical, magnetic, optical, and biological properties tailored to suit specific material applications [28,29,31]. Preliminary investigations of infiltrating STFs with various organic materials such as bulk polymers $[32,33]$, polymer brushes [34,35], and FN [36] have demonstrated that organic materials can be immobilized within the intercolumnar pore space of STFs to enable these substrates to deliver therapeutic biomolecules for biomaterial, tissue engineering, and nonviral gene delivery applications. Current industrial applications of GLAD nanostructured thin films include optical coatings for photovoltaics [37-39], sensing (chemical, biological, optical, and pressure) [25], micro- and nano-fluidics [40], nanoelectronics [29,31], and have been explored as biomaterials [41].

In addition to the precise control over STF fabrication, the nanocolumnar architecture provided by STFs allows for sensitive optical detection by GE due to the optical anisotropy provided by the nanocolumn orientation of the STFs $[28,33,36,42,43]$. Recently, investigations of infiltrating STFs with various organic materials such as bulk polymers [32,33], polymer brushes [34,35], and fibronectin (FN) [36] have demonstrated that organic materials can be immobilized within the intercolumnar pore space of STFs. Generalized ellipsometry has been used in conjunction with quartz crystal microbalance with dissipation (GE/QCM-D) to characterize the dynamic adsorption processes of organic molecules to both flat and nanostructured STF substrates [34-36,44-46]. While protein loading has been evaluated extensively on flat surfaces, evaluation of protein adsorption to/within nanostructured thin 
films is sparse due to the lack of effective methods to evaluate the three-dimensional distribution of proteins within nanostructured features.

The FN protein adsorption studies described in this paper aim to elucidate the influences of highly ordered nanostructured columnar features, such as column orientation, nanocolumn surface density (spacing), and total surface area, on FN adsorption and loading. FN was chosen for protein adsorption studies since FN is a commonly used ECM protein to coat biomaterial substrates for the purpose of enhancing cell adhesion and cellmaterial interactions [23,47-53]. The present investigation is unique relative to previous GE/QCM-D investigations of biomolecule adsorption since GE is used here to discriminate between FN adsorption to the top of three-dimensional nanostructured columnar substrates and the FN loading within the intercolumnar pore spaces of nanostructured substrates. Since both surface adsorbed proteins and substrate nanotopographies have been previously shown to independently enhance cell behaviors, such as cell adhesion, spreading, and proliferation, the current investigation also aims to evaluate cell-material interactions and biocompatibility as a function dependent on both precisely defined substrate nanotopographies and enhanced protein loading within nanostructured surfaces $[1,40,41$, 54,55]. These three-dimensional nanostructured STFs loaded with FN are hypothesized to be excellent candidates for use as biomaterial substrates to load and release biomolecules and to enhance cell-substrate interactions for applications in drug delivery, tissue engineering, and diagnostics.

\section{Materials and methods}

\subsection{Sample preparation}

STFs were fabricated by electron beam evaporation of titanium (Ti) pellets (Super Conductor Materials, Inc., Tallman, New York) onto either gold-coated quartz crystal microbalance (QCM) sensors (Q-Sense Inc., Linthicum Heights, Maryland) for protein adsorption studies or onto silicon wafers (University Wafer, South Boston, Massachusetts) for cell culture studies. Details regarding specific STF deposition parameters are included in the Supplemental methods Section S1.1. Immediately following the fabrication of STFs, generalized ellipsometry (GE) measurements of STFs were acquired using a Woollam M-2000 spectroscopic ellipsometer (J. A. Woollam Co., Inc., Lincoln, Nebraska) to confirm deposited film thicknesses and column slanting angles. The procedures for acquiring GE measurements of STFs to confirm film thickness, column slanting angle, and volume fractions (related to column spacing) are similar to previously published STF ellipsometric procedures $[28,33,36,43]$, and specific details regarding GE data acquisition and modeling are included in the Supplemental methods Section S1.2.

\subsection{Combined generalized ellipsometry and dissipative quartz crystal microbalance}

The combinatorial GE/QCM-D setup consists of an E1 QCM-D (Q-Sense, Inc.) module, mounted to the sample stage of a M-2000 spectroscopic ellipsometer (J. A. Woollam Co., Lincoln, Nebraska). QCM-D wafers containing either STFs or flat Ti thin films were mounted within the QCM-D liquid chamber, which contains windows for the ellipsometer's light beam to pass through the cell at a $65^{\circ}$ angle of incidence, allowing for dynamic 
molecular adsorption analysis using both instruments simultaneously. Upon acquiring baseline GE measurements that are necessary for subsequent modeling of spectral data, 1× phosphate buffered saline (PBS) (Life Technologies, Carlsbad, California) solution was introduced into the liquid chamber at a constant rate of $0.1 \mathrm{~mL} / \mathrm{min}$ using an Ismatec IPC 8 peristaltic pump (IDEX Health and Science GmbH, Wertheim-Mondfeld, Germany) and Tygon tubing (U.S. Plastic Corp., Lima, Ohio) connected to the liquid chamber. Then, $10 \mu \mathrm{g} / \mathrm{mL}$ human plasma FN (Sigma-Aldrich, St. Louis, Missouri) flowed through the liquid chamber for 90 min. Following FN adsorption, 1× PBS was used to rinse nonadsorbed FN from the surfaces for $30 \mathrm{~min}$. The data modeling procedures for GE/QCM-D measureme $\mu$ nts are included in the Supplemental methods Sections S1.2 and S1.3, and additional information on GE/QCM-D data acquisition and modeling is available in previously published literature $[34,36,44-46]$.

\subsection{Cell studies}

Samples for cell culture were prepared by cutting the wafers with a razor to fit into the bottom of standard 48-well tissue culture polystyrene well-plate (Corning, Tewksbury, Massachusetts). Samples were cleaned with copious rinsing in 200 proof sterile-filtered ethanol (EtOH), followed by air drying for $30 \mathrm{~min}$. and subsequent rinsing in PBS prior to FN coating and/or cell seeding. Samples that were treated with protein prior to cell seeding were coated with FN in 48-well plates by incubating samples in $200 \mu \mathrm{L}$ of $10 \mu \mathrm{g} / \mathrm{mL}$ FN at room temperature for $90 \mathrm{~min}$, followed by rinsing with $1 \times$ PBS. Then, NIH/3T3 mouse fibroblasts (ATCC, Manassas, Virginia) were plated at a concentration of 15,000 cells per well using Dulbecco's Modified Eagle's Media (DMEM, ATCC) containing 10\% calf serum (Colorado Serum Co., Denver, Colorado) and 1\% penicillin/streptomycin (Invitrogen, Carlsbad, California), and incubated at $37^{\circ} \mathrm{C}, 5 \% \mathrm{CO}_{2}$. Culture of D1/ORL/UVA (ATCC) mouse mesenchymal stem cells (mMSCs) was also evaluated by seeding 25,000 cells per well and culturing in DMEM containing 10\% fetal bovine serum (Invitrogen), 1\% penicillin/streptomycin (Invitrogen), and incubated at $37^{\circ} \mathrm{C}, 5 \% \mathrm{CO}_{2}$. Cell viability was assayed with a Live/Dead Cell Viability Assay staining kit (Invitrogen), $48 \mathrm{~h}$ following cell seeding, according to the manufacturer's protocols. Cell proliferation was measured at $24 \mathrm{~h}$ following cell seeding using a water-soluble tetrazolium cell proliferation assay kit (WST-1 assay, Roche Applied Science, Indianapolis, Indiana) according to the manufacturer's protocols. Additional details regarding both the Live/Dead staining and the WST-1 cell proliferation assay are included in Supplemental methods Section S1.4.

\subsection{Statistics}

All modeled ellipsometric values presented in Table 1 are reported as an average for three samples with corresponding standard error values. All GE/QCM-D protein adsorption measurements were conducted in triplicate on different days. For the analysis of protein adsorption (Fig. 2), a total of 90 data points (30 data points from each replicate experiment, gathered within the final $20 \mathrm{~min}$. of each measurement) were evaluated and mean protein adsorption values are reported as the mean \pm standard error. All cell studies were conducted with triplicate samples cultured in different wells. One-way ANOVA statistical analysis with Tukey's post-tests were conducted using Prism 5.0 graphing and statistical 
analysis software (Graph Pad, La Jolla, California) at a 95\% confidence level ( $\alpha=0.05)$ to make statistical comparisons between all STF and flat control surfaces for all protein loading and cell culture investigations.

Table 1. Structural characteristics of GLAD substrates following deposition

\begin{tabular}{|c|c|c|c|}
\hline & SCTF & VCTF & ppSCTF \\
\hline Film thickness (nm) ${ }^{\mathrm{a}}$ & $103.15 \pm 3.33$ & $96.35 \pm 1.57$ & $101.07 \pm 0.43$ \\
\hline Nanocolumn slanting angle (deg. w.r.t. normal)a & $50.27 \pm 1.54$ & 0 (fixed) & $32.60 \pm 0.13$ \\
\hline STF fraction $(\%)^{a}$ & $17.09 \pm 2.11$ & $21.73 \pm 0.59$ & $12.97 \pm 1.03$ \\
\hline Avg. nanocolumn diameter $(\mathrm{nm})^{\mathrm{b}}$ & $35.92 \pm 1.47$ & $34.62 \pm 2.69$ & $41.49 \pm 1.27$ \\
\hline Avg. nanocolumn length $(\mathrm{nm})^{\mathrm{c}}$ & 155.12 & 92.35 & 115.22 \\
\hline Avg. nanocolumn surface area $\left(\mu \mathrm{m}^{2}\right)^{\mathrm{c}}$ & $1.95 \mathrm{e}^{-02}$ & $1.19 \mathrm{e}^{-02}$ & $1.77 \mathrm{e}^{-02}$ \\
\hline Avg. nanocolumn volume $\left(\mu \mathrm{m}^{3}\right)^{\mathrm{c}}$ & $1.57 \mathrm{e}^{-04}$ & $8.69 \mathrm{e}^{-05}$ & $1.56 \mathrm{e}^{-04}$ \\
\hline $\begin{array}{l}\text { Nanocolumn surface density (avg. number of } \\
\left.\text { nanocolumns } / \mu \mathrm{m}^{2}\right)^{\mathrm{c}, \mathrm{d}}\end{array}$ & 112.1 & 240.8 & 84.2 \\
\hline Total surface area of nanocolumn tips $\left(\mu \mathrm{m}^{2}\right)^{\mathrm{c}, \mathrm{d}}$ & 0.114 & 0.227 & 0.114 \\
\hline Total surface area between nanocolumns $\left(\mu \mathrm{m}^{2}\right)^{\mathrm{c}, \mathrm{d}}$ & 0.886 & 0.773 & 0.886 \\
\hline Total surface area of nanocolumns $\left(\mu \mathrm{m}^{2}\right)^{\mathrm{c}, \mathrm{d}}$ & 2.190 & 2.872 & 1.492 \\
\hline Total enhancement in surface area $\left(\mu \mathrm{m}^{2}\right)^{\mathrm{c}, \mathrm{d}}$ & 3.076 & 3.645 & 2.372 \\
\hline
\end{tabular}

a. GE measured parameter

b. SEM measured parameter

c. Geometric analysis using GE and SEM measured values, assuming individual STF nanocolumns shaped as cylindrical inclusions within the total volume of the thin film

d. Results of these geometric analyses are reported with respect to $1 \mu \mathrm{m}^{2}$ two-dimensional surface area.

\section{Results}

\subsection{Characterization of STFS}

Electron beam facilitated GLAD was used to fabricate STFs to evaluate protein loading and cell-instructive properties of nanocolumnar thin film arrays. Following substrate fabrication, spectral analysis of GE measurements was conducted to confirm the physical dimensions of the STFs and flat control substrates (Scheme 1). A summary of modeled optical data, which describe the physical dimensions for all substrates used in subsequent FN adsorption and cell studies are included in Table 1. The GE measurements of both STF and flat surfaces indicate that all substrates were deposited near the desired film thickness of $100 \mathrm{~nm}$ (Table 1). Figure 1 contains SEM images of SCTF (Fig. 1A), VCTF (1C), ppSCTF (1E), and flat Ti (1G) substrates without adsorbed FN, which also indicate films deposited with approximate thicknesses of $100 \mathrm{~nm}$. These images qualitatively confirm the structural parameters quantified by the GE modeled parameters, though the nanocolumns are not as structurally uniform compared to the nanocolumns of respective as-deposited STFs (Fig. S1) that were imaged by SEM immediately following GLAD deposition. The comparison between respective samples on Figs. 1 and S1 demonstrate that the nanocolumn disorder seen on Fig. 1 is due to (a) the lyophilization and gold sputtering steps performed prior to obtaining images of the samples, (b) the treatment necessary to deposit the FN, and (c) the cleaved edges were exposed to unwanted mechanical forces during the 2 treatment steps 
in (a) and (b). By combining the GE measured STF parameters (Table 1a) with a measure of average STF parameters measured in SEM images using NIH ImageJ 64 (Table $1^{\mathrm{b}}$ ), an additional geometric analysis of the physical properties of STFs (Table 1c) was conducted, including calculations of nanocolumn length, surface area, volume, and nanostructure surface area enhancement relative to flat surfaces. This analysis indicates that PpSCTF substrates possess a wider intercolumnar spacing than both SCTFs and VCTFs, due to the lower ppSCTF nanoscolumn density. Furthermore, VCTFs exhibit the greatest total surface area with a 3.6-fold enhancement of surface area relative to flat surfaces (Table 1). The STF nanocolumn surface areas and nanocolumn densities (Table 1,d), calculated using GE and SEM measured values, are reported as area values normalized to $1 \mu \mathrm{m}^{2}$ two-dimensional unit area. These STF physical properties were subsequently correlated to FN adsorption and cell-material interactions on STFs.

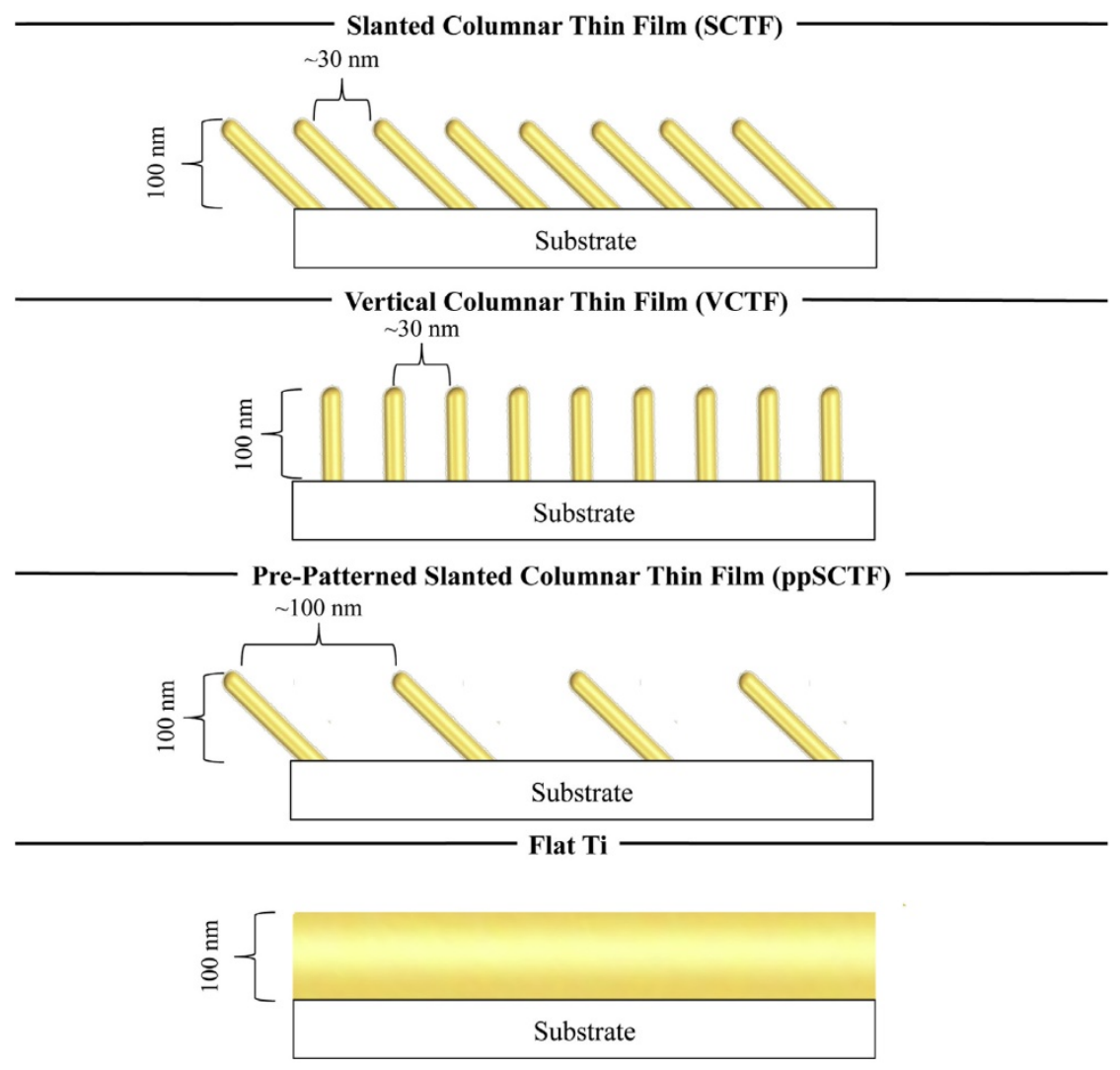

Scheme 1. Classifications of STF and flat substrates evaluated in protein adsorption and biocompatibility studies. 

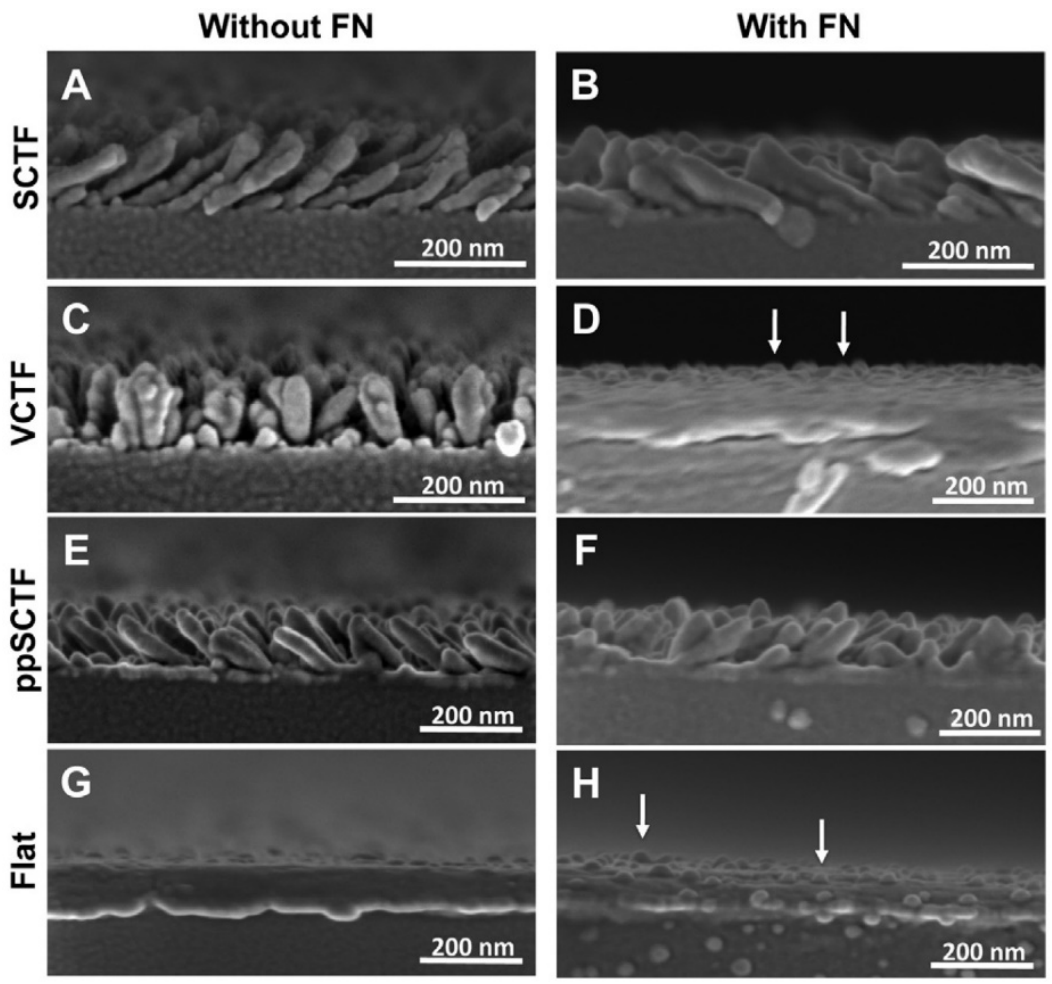

Figure 1. Scanning electron microscopy images of SCTF, VCTF, ppSCTF, and flat substrates without FN (A, C, E, and G, respectively) and substrates with FN (B, D, F, and H, respectively). Scale bars included on all images represent a length of $200 \mathrm{~nm}$.

\subsection{FN adsorption to nanostructured STFs}

Upon analysis of the structural properties of the GLAD STFs, FN protein was introduced and allowed to adsorb to the surfaces. SEM images acquired after FN adsorption (Fig. 1B, $\mathrm{D}, \mathrm{F}$, and $\mathrm{H}$ ) indicate that FN can coat individual nanocolumns as well as penetrate the intercolumnar spaces, while STFs retain their respective structural morphologies upon FN immobilization. For example, individual slanted columns of both SCTFs and ppSCTFs are observed to change from a roughened, granular columnar surface prior to FN adsorption (Fig. 1A and E, respectively) to smooth columns following FN adsorption (Fig. 1B and F, respectively), while retaining a slanted columnar morphology. Although VCTFs were observed to have a similar granular surface roughness prior to FN adsorption (Fig. 1C), VCTFs were nearly completely covered and infiltrated with FN following FN adsorption (Fig. 1D). The dome-shaped protrusions observed on top of the VCTF + FN surface (examples are indicated with arrows on Fig. 1D) could not be accurately identified, but are speculated to be either protrusions of VCTF column tips or FN aggregates on top of the substrate. Upon adsorbing FN to flat Ti substrates, small domes on the surface (examples indicated with arrows on Fig. $1 \mathrm{H}$ ) were also observed. The presence of these domes on the flat substrate leads to speculation whether the domes could be FN aggregates or VCTF nanocolumn tips. 
Next, combinatorial GE/QCM-D was used to quantify, in real-time, the mass of adsorbed FN to STFs and to discriminate between FN adsorbed either on top (GEтоP) or within (GEемA) STF nanocolumns (Scheme 2). The total average mass of adsorbed FN detected by the GEтор modeled parameter is shown in Figure 2 and representative GE/QCM-D measurements demonstrating FN adsorbed mass as a function of time are shown on Supplemental Figure S2. The average mass of FN adsorbed on top of flat substrates upon rinsing with PBS was $3.76 \pm 0.03 \mathrm{mg} / \mathrm{m}^{2}$ (Fig. 2A). Comparisons between the FN adsorbed mass on top of the different STF substrates indicated that VCTF substrates contained the most FN adsorbed on top of the surface $\left(\right.$ GEтор $\left.=1.32 \pm 0.21 \mathrm{mg} / \mathrm{m}^{2}\right)$, significantly greater $(p<0.01)$ than the mass of adsorbed FN on top of ppSCTF surfaces (GEтор $=0.56 \pm 0.22 \mathrm{mg} / \mathrm{m}^{2}$ ). Furthermore, the average mass of adsorbed FN on top of SCTFs was $1.11 \pm 0.05 \mathrm{mg} / \mathrm{m}^{2}$, and not statistically different than adsorbed FN mass to either VCTFs or ppSCTFs. Overall, these results combined with the geometric analysis of STF physical properties (Table 1) indicate that the VCTFs enhance FN adsorption on top of the columns, relative to both SCTFs and ppSCTFs, due to the enhanced surface area of the VCTF nanocolumn tips (approx. $0.227 \mu \mathrm{m}^{2}$ for VCTFs compared to $0.114 \mu \mathrm{m}^{2}$ for both SCTFs and ppSCTFs). This increase in nanocolumn tip area at the surface of VCTFs is the result of the increased density of vertical nanocolumns (approx. 240 nanocolumns $/ \mu \mathrm{m}^{2}$ ) compared to the SCTF (approx. 112 nanocolumns $/ \mu \mathrm{m}^{2}$ ) and ppSCTF (approx. 84 nanocolumns $/ \mu \mathrm{m}^{2}$ ) calculated nanocolumn densities (Table 1).

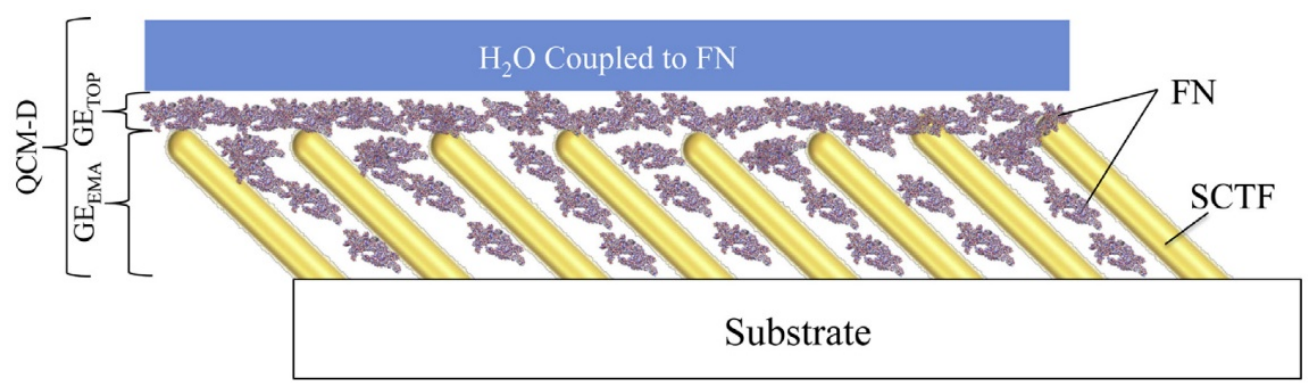

Scheme 2. Schematic representation of GE/QCM-D measured parameters for protein adsorption to nanostructured STF surfaces. 
FN Mass Adsorbed on Top of Nanocolumns

$\mathrm{GE}_{\text {TOP }}$

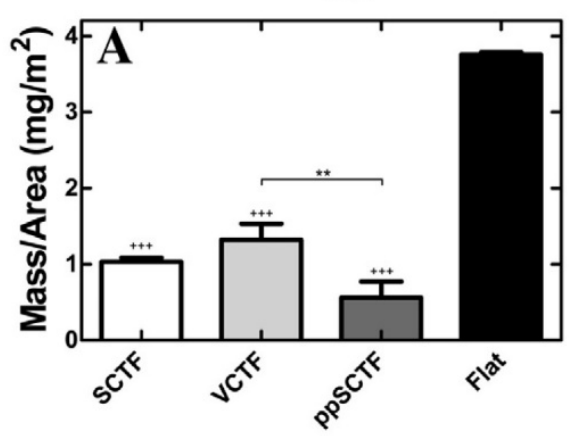

Total FN Mass

GE $_{\text {TOTAL }}$

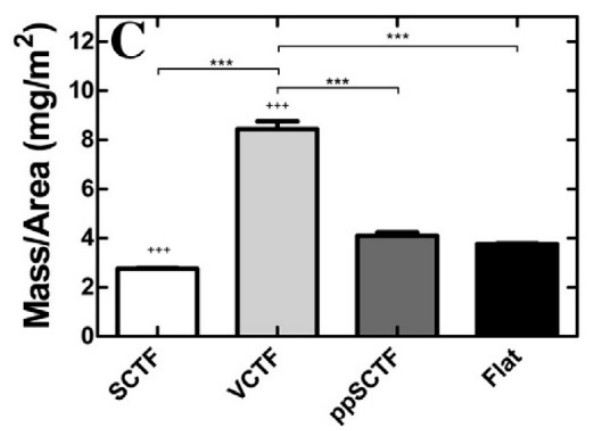

FN Mass in between Nanocolumns $\mathbf{G E}_{\text {EMA }}$

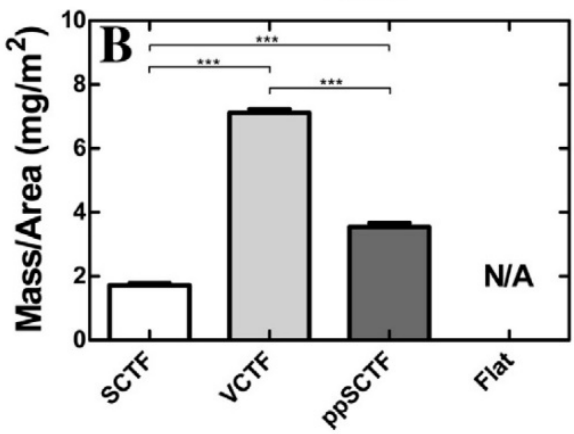

Total FN \& Coupled Solvent Mass QCM-D

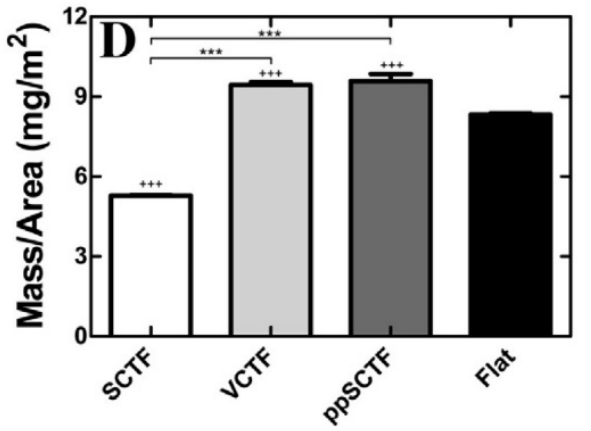

Figure 2. Summary of the total average mass of adsorbed $\mathrm{FN}$ for each modeled parameter measured by GE/QCM-D, which includes the GEtop (A), GEema (B), GEтотAL (C), and QCM-D (D) measured parameters. The adsorption mass data reported here are the average and associated standard error of adsorbed FN following a PBS rinse phase for pooled sets of triplicate experiments per substrate condition. A one-way ANOVA with Tukey's post-test ( $\alpha=0.05,95 \%$ confidence interval) was used for all FN adsorbed mass comparisons between substrate conditions $\left({ }^{* *} p<0.01\right.$ and ${ }^{* * *} p<0.001$ for comparisons between STFs and ${ }^{++} p<0.001$ for comparisons of STFs against the respective flat Ti control).

The GEema parameter uses an effective medium approximation (EMA) approach to determine the mass of adsorbed FN within the STF intercolumnar void spaces (Scheme 2). The comparison of the adsorbed mass of FN within the STFs (Fig. 2B) indicates that the GEEма measured FN mass was significantly greater within VCTF columns $(7.11 \pm 0.11$ $\left.\mathrm{mg} / \mathrm{m}_{2}\right)$ compared to either SCTFs or ppSCTFs $(p<0.001)$. Specifically, the average FN adsorbed mass within VCTFs was 4-fold greater than FN mass within the columns of the SCTFs $\left(1.81 \pm 0.06 \mathrm{mg} / \mathrm{m}^{2}\right)$ and 2-fold greater than FN mass within the columns of the ppSCTFs $\left(3.52 \pm 0.013 \mathrm{mg} / \mathrm{m}^{2}\right)$, as shown in Fig. 2B. The enhancement of protein loading within VCTFs relative to SCTFs and ppSCTFs also correlates to the increase in VCTF surface area relative to SCTFs and ppSCTFs (Table 1). Furthermore, the comparison of adsorbed FN mass within SCTFs and ppSCTFs, both with slanted columnar morphologies, indicates that 
ppSCTFs with a low nanocolumn density (hence increased ambient pore space within the total three-dimensional volume) relative to SCTFs (Table 1) can significantly increase the amount of FN that can penetrate the intercolumnar void space 2-fold ( $p<0.001$, Fig. 2B). These findings indicate that both STF surface area and column density influence the degree of FN adsorption within STFs. Both GEтор and GEемA measured parameters were combined to determine the total GE measured mass (GEтотаL, Fig. 2C), which demonstrates that VCTF substrates, with a 3.6-fold greater unit surface area relative to flat substrates, enhance the total FN adsorbed mass two-fold relative to flat substrates (Fig. 2C).

The QCM-D measured parameter describes the total mass of FN and coupled solvent molecules both within STFs and on top of surfaces. Figure 2D includes the summary of averaged total FN adsorption measured by QCM-D, while the red lines on Figure S2 indicate representative QCM-D measurements of FN adsorption. The adsorption trends measured by QCM-D were similar to trends reported by GE. For example, the QCM-D measured FN mass on flat substrates was 1.5-fold greater $(p<0.001)$ than the FN mass on SCTFs, while the measured FN mass on both VCTF and PPSCTF substrates were greater than on flat and SCTF substrates $(p<0.001)$. The QCM-D results further confirm the trends demonstrated by the GE modeled parameters, however QCM-D was not able to distinguish between FN and coupled solvent molecules or between FN adsorption to different locations within and on top of the STFs.

\subsection{STF nanotopography affects cellular response}

The ability of STFs, both with and without FN, to support cell culture was investigated by conducting cell adhesion, viability, and proliferation assays. Figure 3 contains representative, overlaid Live/Dead images for live (green fluorescing cytoplasm) and dead (red fluorescing nuclei) NIH/3T3 cells cultured on SCTF, VCTF, ppSCTF, and flat control substrates, both without adsorbed FN (Fig. 3A-D) and with adsorbed FN (Fig. 3E-H). Corresponding Live/Dead stain images for D1/ORL/UVA mMSCs seeded on STFs are also included in Figure 3I-P. Analysis of NIH/3T3 mouse fibroblast cell adhesion (Fig. 4A) indicates that all STF nanotopographies significantly enhanced cell adhesion compared to the flat control condition ( $p<0.001$ for all comparisons, except $p<0.01$ between VCTFs and flat). For example, 3T3 cell adhesion was 15-fold greater on ppSCTF surfaces (1043 \pm 63 cells) compared to flat Ti substrates ( $68 \pm 35$ cells). Upon evaluating cell adhesion of mMSCs on STFs (Fig. 4B), only ppSCTF substrates were found to significantly enhance mMSC adhesion relative to all other substrate conditions investigated ( $p<0.001$ for all comparisons), with mMSC adhesion to ppSCTFs (646 \pm 90 cells) enhancing 6-fold with respect to flat Ti substrates $(108 \pm 32$ cells). 


\section{NIH/3T3 Mouse Fibroblasts}
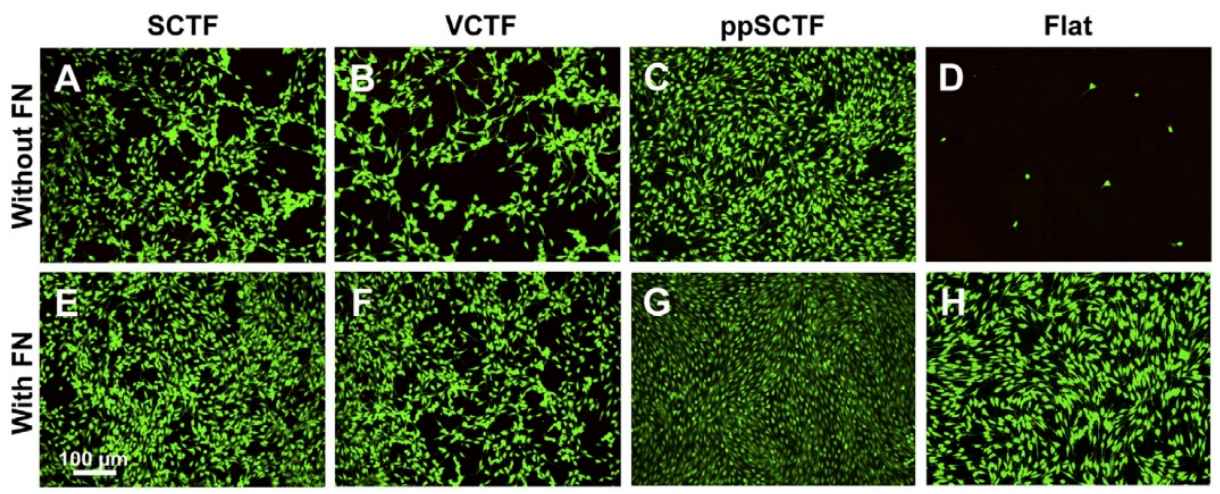

D1/ORL/UVA Mouse Mesenchymal Stem Cells
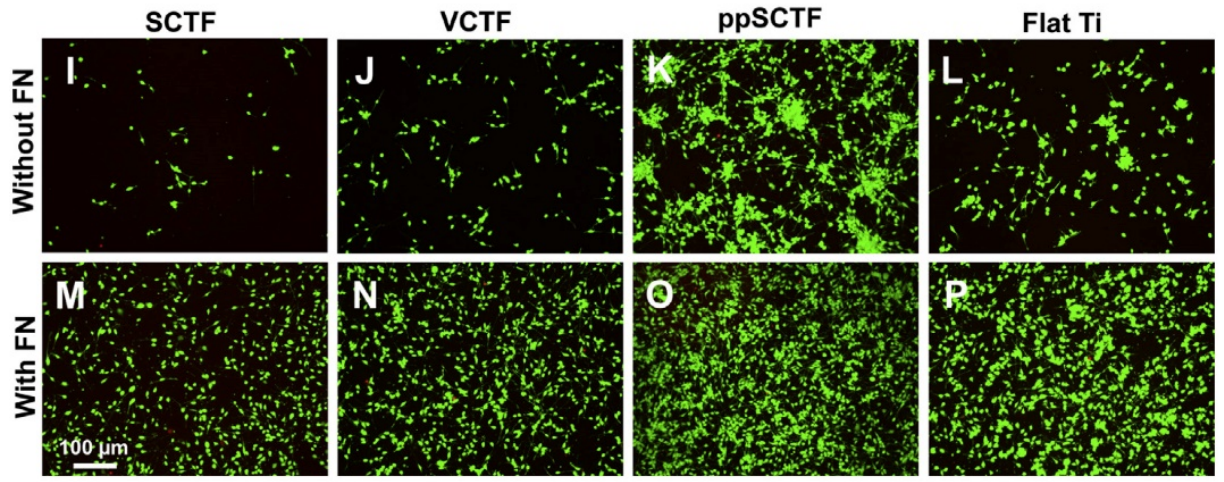

Figure 3. Fluorescence photomicrographs of Live/Dead cell assays on NIH/3T3 mouse fibroblasts (A-H) and D1/ORL/UVA mMSCs (I-P) cultured on SCTF (A and I), VCTF (B and J), ppSCTF (C and $\mathrm{K})$, and flat (D and $\mathrm{L}$ ) substrates without FN, as well as SCTF + FN $(\mathrm{E}$ and $\mathrm{M}), \mathrm{VCTF}+\mathrm{FN}(\mathrm{F}$ and N), ppSCTF + FN (G and O), and flat Ti + FN (H and P) substrates. The cytoplasm of live cells is stained with an acetomethoxy derivative of Calcein (AM) and fluoresce green, while the nuclei of dead cells are stained with ethidium homodimer-1 (EthD-1) and fluoresce red. Scale bars $=100 \mu \mathrm{m}$. 

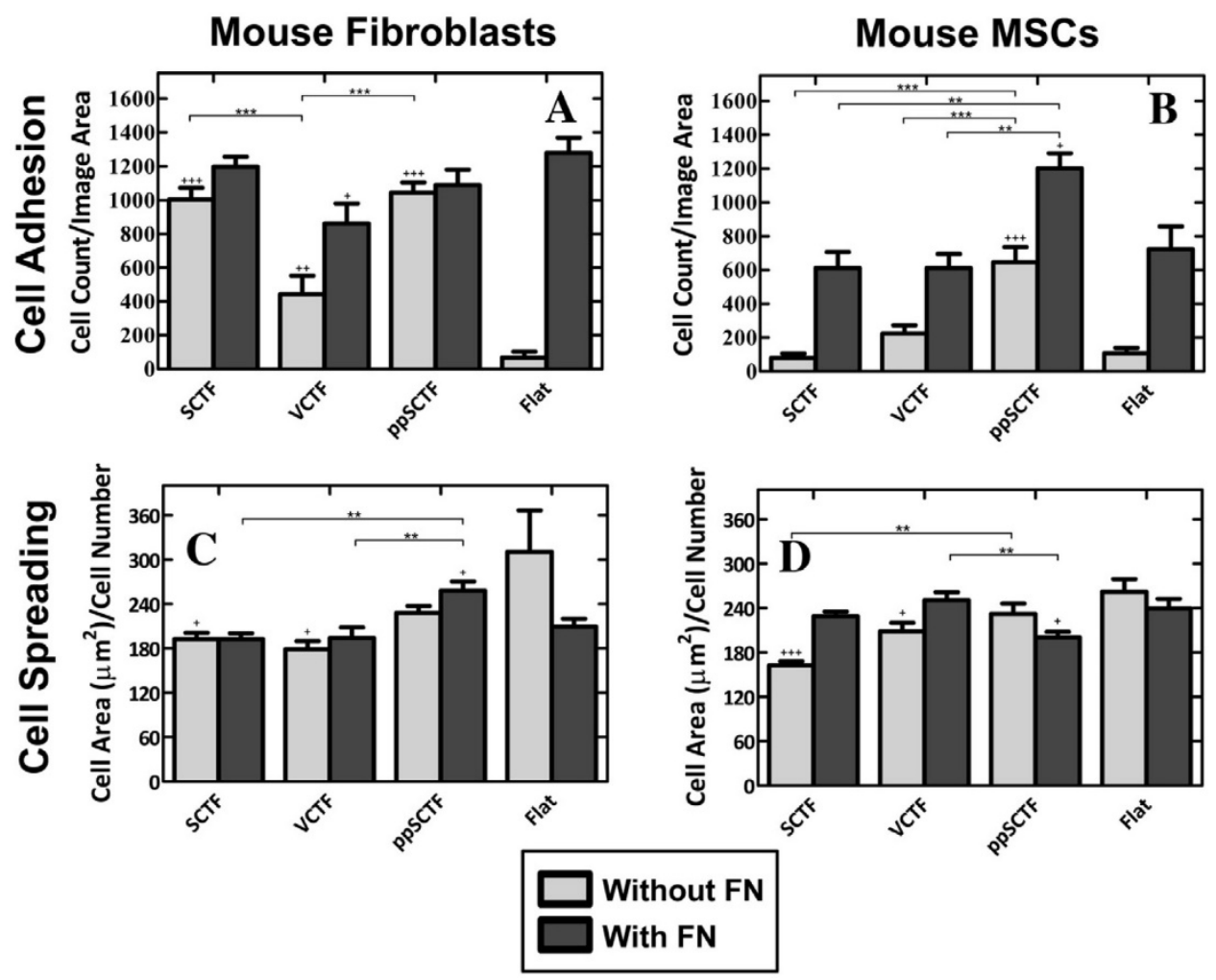

Figure 4. Cell adhesion for NIH/3T3 mouse fibroblasts (A) and D1/ORL/UVA mMSCs (B) as well as cell spreading for NIH/3T3 mouse fibroblasts (C) and D1/ORL/UVA mMSCs (D) for cells seeded on substrates without adsorbed FN (light gray bars) and with adsorbed FN (dark gray bars). Tukey's post-test statistical comparisons between cell characteristics on the various substrates are indicated by asterisks $\left({ }^{*} p<0.05,{ }^{* *} p<0.01,{ }^{* * *} p<0.001\right.$ for comparisons between STFs and ${ }^{+} p<0.05,{ }^{++} p<0.01,{ }^{+++} p<0.001$ for comparisons of STFs against the respective flat $\mathrm{Ti}$ control).

Cell adhesion was examined on STFs with adsorbed FN loaded within the STF intercolumnar pore spaces. The comparisons between light and dark gray bars for each group of substrates on Figure $4 \mathrm{~A}$ and $\mathrm{B}$ indicate the differences in cell adhesion between substrates without adsorbed FN and those with adsorbed FN. For mouse fibroblasts, the addition of FN resulted in a 2-fold increase in cell adhesion on VCTF + FN surfaces $(p<0.05)$ as compared to VCTFs without FN, while no significant differences in cell adhesion were observed on SCTF + FN and ppSCTF_FN surfaces relative to SCTFs and ppSCTFs without FN, respectively. mMSC adhesion on all STF + FN substrates was significantly enhanced relative to the respective uncoated STFs $(p<0.001$ for all comparisons, except $p<0.05$ for VCTFs). Comparisons of NIH/3T3 mouse fibroblast cell adhesion between all surfaces with adsorbed FN suggest that no significant differences exist between cell adhesion on SCTF + FN, VCTF + FN, and ppSCTF + FN substrates (black bars on Fig. 4A). However, D1/ORL/ UVA mMSC adhesion between surfaces containing FN (black bars on Fig. 4B) suggest a different response than fibroblasts, since the mMSC adhesion on ppSCTF + FN surfaces 
(1201 \pm 90 cells) was 2 -fold greater than cell adhesion on SCTF + FN (612 \pm 94 cells), VCTF + FN (611 \pm 84 cells), and flat Ti + FN (723 \pm 135 cells) substrates ( $p$-value at least $<0.05$ for all comparisons).

For both cell types seeded on STFs without FN, the average cell spreading was significantly greater on flat control substrates $\left(311 \pm 56 \mu \mathrm{m}^{2} / 3 \mathrm{~T} 3\right.$ cell and $262 \pm 17 \mu \mathrm{m}^{2} / \mathrm{mMSC}$ cell) relative to both SCTF and VCTF substrates ( $p<0.05$ for all comparisons except $p<0.001$ for mMSCs on SCTFs), while cell spreading on ppSCTFs was not statistically different from the flat control for both cell types (Fig. 4C and D). For both cell types, the mean cell spreading on ppSCTF substrates $\left(228 \pm 9 \mu \mathrm{m}^{2} / 3 \mathrm{~T} 3\right.$ cell and $232 \pm 14 \mu \mathrm{m}^{2} / \mathrm{mMSC}$ cell) was greater than on SCTFs $\left(193 \pm 8 \mu \mathrm{m}^{2} / 3\right.$ T3 cell and $162 \pm 6 \mu \mathrm{m}^{2} / \mathrm{mMSC}$ cell), which suggest that ppSCTFs with decreased nanocolumn density relative to SCTFs (Table 1), can enhance cell spreading. The comparisons between substrates without or with adsorbed FN (comparisons between light and dark bars for each substrate on Fig. 4C and D) indicate that the addition of FN did not significantly enhance cell spreading for either mouse fibroblasts (Fig. 4C) or mMSCs (Fig. 4D) on all surfaces that were evaluated. The only significant difference in cell spreading between surfaces either with or without FN was observed for mMSCs on SCTFs, where spreading was enhanced 1.4-fold from $162 \pm 6 \mu \mathrm{m}^{2} /$ cell on SCTF to $229 \pm 6 \mu \mathrm{m}^{2} /$ cell on SCTF + FN surfaces $(p<0.01)$. For comparisons of cell spreading among surfaces containing adsorbed FN, the analysis of mouse fibroblast cell spreading indicates that ppSCTF $+\mathrm{FN}$ substrates support the highest degree of cell spreading relative to cells cultured on SCTF + FN $\left(193 \pm 8 \mu \mathrm{m}^{2} /\right.$ cell; $\left.p<0.01\right)$, VCTF + FN $\left(194 \pm 14 \mu \mathrm{m}^{2} /\right.$ cell; $p<0.01)$, and flat Ti + FN $\left(210 \pm 11 \mu \mathrm{m}^{2} /\right.$ cell; $\left.p<0.05\right)$ surfaces. However, for mMSCs adhered to surfaces containing FN, a different trend was observed since cells were the least spread on ppSCTF + FN surfaces $\left(200.63 \pm 7.23 \mu \mathrm{m}^{2} /\right.$ cell; significantly less than cell spreading on VCTF + FN $(p<0.01)$ and flat Ti + FN $(p<0.05)$ surfaces. These results indicate that (a) cell spreading on STFs containing FN is cell-type dependent, and (b) that enhanced FN loading to both VCTF and ppSCTF nanostructured surfaces relative to flat substrates (described in Section 3.2) correlates to enhanced cell adhesion and spreading on VCTF + FN and ppSCTF + FN surfaces compared to SCTF + FN and flat Ti + FN surfaces.

Cell proliferation is presented in Figure 5A for mouse fibroblasts and Figure 5B for mMSCs cultured on STFs. The cell proliferation for both mouse fibroblasts and mMSCs was found to be significantly enhanced for cells adhering to ppSCTFs $(1.71 \pm 0.18$ O.D. $\left(\lambda_{430}\right) / \mathrm{cm}^{2}$ and $2.16 \pm 0.27$ O.D. $\left(\lambda_{430}\right) / \mathrm{cm}^{2}$, respectively), compared to all other STF and flat control substrates (Fig. 5A and B; $p$-value at least $<0.05$ for all comparisons). Since there were no statistical differences between the SCTF, VCTF, and flat control substrates for both cell types, these findings suggest that PPSCTF substrates enhance cell proliferation relative to nanotopographies with higher nanocolumn densities, such as SCTFs and VCTFs, as well as flat surfaces. For both cell types investigated, the addition of FN was not found to significantly enhance cell proliferation on any of the STF substrates investigated as indicated by the comparisons between light and dark gray bars on Figure 5A and B (n.s. at $\alpha=0.05$ ). Furthermore, the comparisons of cell proliferation between substrates containing adsorbed FN indicate similar trends as observed for comparisons between non-FN substrates, where ppSCTF + FN substrates were found to significantly enhance cell proliferation relative to all STF + FN and flat Ti + FN substrates investigated (Fig. 5A and B). For example, mouse 
fibroblast cell proliferation on ppSCTF + FN substrates $\left(1.80 \pm 0.10\right.$ O.D. $\left.\left(\lambda_{430}\right) / \mathrm{cm}^{2}\right)$ was enhanced approximately 2 -fold relative to cell proliferation on SCTF + FN $(0.84 \pm 0.06$ O.D. $\left.\left(\lambda_{430}\right) / \mathrm{cm}^{2}, p<0.05\right)$ and VCTF + FN $\left(1.09 \pm 0.09\right.$ O.D. $\left.\left(\lambda_{430}\right) / \mathrm{cm}^{2}, p<0.01\right)$ substrates. Similarly, mMSC proliferation on ppSCTF + FN substrates $\left(2.04 \pm 0.35\right.$ O.D. $\left.\left(\lambda_{430}\right) / \mathrm{cm}^{2}\right)$ was enhanced approximately 4 -fold relative to cell proliferation on SCTF + FN $(0.43 \pm 0.06$ O.D. $\left.\left(\lambda_{430}\right) / \mathrm{cm}^{2}, p<0.05\right)$ and VCTF $+\mathrm{FN}\left(0.62 \pm 0.42\right.$ O.D. $\left.\left(\lambda_{430}\right) / \mathrm{cm}^{2}, p<0.05\right)$ substrates.

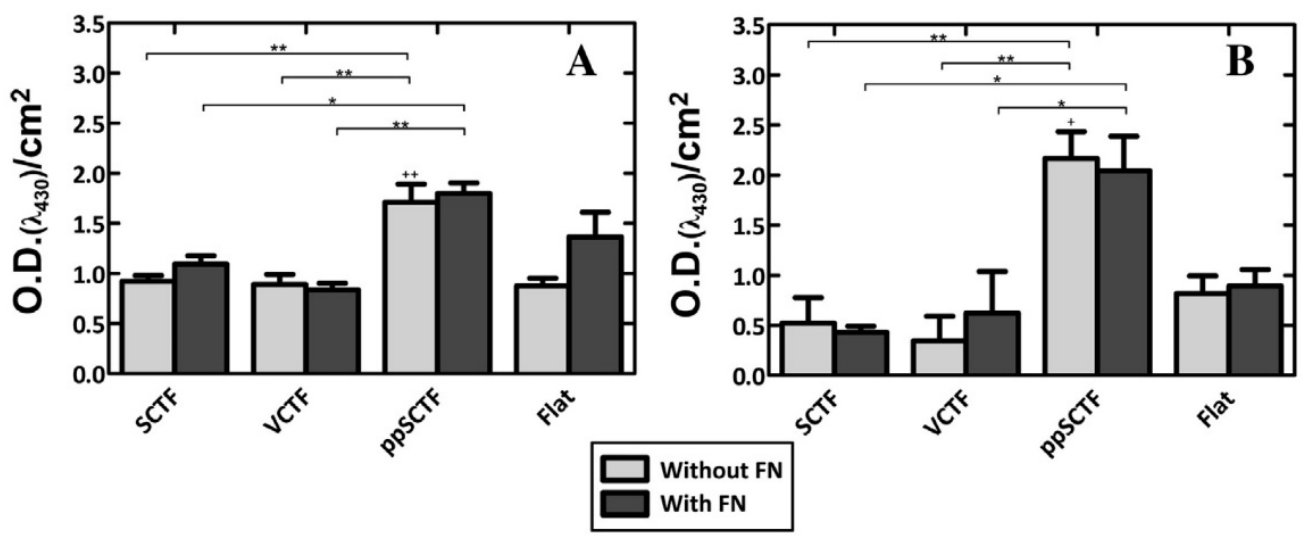

Figure 5. Cell proliferation of NIH/3T3 mouse fibroblasts (A) and D1/ORL/UVA mMSCs (B) acquired using water soluble tetrazolium (WST-1) assay and by measuring the calorimetric optical density (O.D.) normalized to the surface area for substrates without adsorbed FN (light gray bars) and with adsorbed FN (dark gray bars). Tukey's post-test statistical comparisons between cell proliferation on the various substrates are indicated by asterisks $\left({ }^{*} p<0.05,{ }^{* *} p<0.01\right.$ for comparisons between STFs and ${ }^{+} p<0.05,{ }^{++} p<0.01$ for comparisons of STFs against the respective flat Ti control).

\section{Discussion}

Nanostructured STF surfaces present highly ordered, three-dimensional, nanoscale substrate features that can increase surface area and enhance optical, magnetic, mechanical, and electrical properties with current applications in photovoltaic solar cell technology [37-39], chemical and biological sensing [25], micro- and nano-fluidics [40], and nanoelectronics $[29,31]$. This investigation demonstrates that GE/QCM-D can dynamically measure the three-dimensional distribution of FN within and around nanostructured STFs and that these surfaces could also be used for biomaterial substrates, with potential applications in biomolecule delivery and tissue engineering. These highly ordered nanostructures could be used to load biomolecules within the STFs by capitalizing on the STF intercolumnar void space. Additionally, the STF nanotopography could be used to direct cell interactions and behaviors, including cell adhesion, shape, migration, and gene expression [8]. Here, STFs were fabricated by GLAD with three different nanocolumnar morphologies (Table 1): (1) SCTFs consisting of slanted columns with a 112 nanocolumn/ $\mu \mathrm{m}^{2}$ nanocolumn packing density, (2) VCTFs consisting of vertical columns and a high nanocolumn density (240 nanocolumns $/ \mu \mathrm{m}^{2}$ ), and (3) ppSCTFs consisting of slanted columns with a low nanocolumn 
density $\left(84\right.$ nanocolumns $\left./ \mu m^{2}\right)$. The physical dimensions of these STF substrates were verified by GE and SEM, then investigated for their potential to load FN within the threedimensional intercolumnar pore spaces and to enhance cell-material interactions relative to flat surfaces.

\subsection{FN Adsorption to STFs}

Combinatorial GE/QCM-D was used to determine the three-dimensional distribution of FN either within or on top of nanocolumn arrays and to determine the influences of nanostructured column orientation and spacing on FN loading within STFs. The benefits to using combinatorial GE/QCM-D over traditional biochemical techniques include dynamic realtime characterization of biomolecule adsorption (allowing for access to parameters not provided by traditional assay techniques such as film thickness, porosity, and rates of adsorption/desorption), noninvasive nature of measurements that leave an intact sample for subsequent experiments, ease and quickness of use. A preliminary study of FN adsorption to Ti-SCTFs has been previously published by our group and has demonstrated the ability of GE/QCM-D to detect protein loading within nanostructured substrates [36]. The current investigation builds on this technique to examine the spatial distribution of adsorbed proteins, either on top of nanostructured columns or loaded within STF nanostructured columnar void spaces. The current study also determined the influence of different STF nanotopographies on FN protein adsorption/loading to nanostructured substrates and demonstrated that STF nanotopographies, such as VCTFs, can enhance protein adsorption relative to flat substrates.

Analysis of the adsorbed FN mass on top of surfaces (GETOP) determined that flat $\mathrm{Ti}$ substrates adsorbed the greatest mass of FN to the top of the two-dimensional flat (nonporous) surface compared to the three-dimensional nanostructured STF substrates. This increased GEтор FN mass on flat substrates relative to STFs was expected, since GE detection of FN adsorption to STFs is broken up into two different parameters that describe FN adsorption either on top of or within STFs (GEтор and GEемA, respectively). However, for studies of FN adsorption to flat substrates, adsorption can occur only on top of the surface. For all STFs there is a limited nanocolumn tip area compared to the top of the flat surface (STF nanocolumn tip area approx. 75-90\% less than flat surface area, Table 1); therefore all STFs adsorbed less FN on the nanocolumn tips than on a flat surface, described by the GEтор parameter. Comparisons between FN adsorbed mass on top of the various STFs (Fig. $2 \mathrm{~A}$ ) indicated that VCTF and SCTF substrates adsorbed the greatest amount of FN to the top of the surface (GEтор $=1.32 \pm 0.21 \mathrm{mg} / \mathrm{m}^{2}$ for VCTFs; $1.11 \pm 0.05 \mathrm{mg} / \mathrm{m}^{2}$ for SCTFs), due to the increased nanocolumnar tip surface areas and nanocolumn densities relative to ppSCTFs (Table 1). While previous work has evaluated the adsorption of different extracellular matrix and serum proteins, such as FN and bovine serum albumin, on different nanostructured surfaces [21,22,55], quantitative analyses, such as immuno-staining, radiolabeling, and calorimetric assays, were not able to determine the fractions of adsorbed proteins either located on top of nanostructured features or within nanostructured features such as spaces, grooves, or pores. Together with the appropriate optical models, GE can effectively discriminate between FN adsorption to specific locations (e.g., either above or within STFs) when using nanostructured substrates. 
The GEema parameter, which describes the amount of FN loaded within the STF intercolumnar pore spaces (Scheme 2), suggests that the differences in STF nanotopography affect the degree to which FN can penetrate within the STF intercolumnar pore space. Increasing the spacing between STF nanocolumns by decreasing the nanocolumn surface density (Table 1), as is the case for ppSCTFs, was found to increase the mass of adsorbed FN within the STF intercolumnar spaces, since the adsorbed FN mass detected by GEEMA within ppSCTFs was significantly greater than the GEema FN mass within SCTFs. Additionally, increasing the total three-dimensional surface area was also shown to enhance FN loading between STF nanocolumns. For example, by preparing STFs with vertical columns (VCTFs), the total three-dimensional surface area relative to both SCTFs and ppSCTFs was increased since the vertical nanocolumns are packed closer together as indicated by the STF fraction and calculated space in between nanocolumns (Table 1). This increased surface area correlates to the enhanced FN loading within VCTFs relative to both SCTFs and ppSCTFs as well as the total (GEтотаL, Fig. 2C) increased FN adsorbed mass measured on VCTFs relative to SCTFs, ppSCTFs, and flat surfaces. Overall, these results suggest that decreasing the nanocolumn density for the purpose of opening the intercolumnar space between slanted columns is an effective strategy to enhance the intercolumnar penetration of FN. However VCTFs, with closely packed vertically oriented nanocolumns, demonstrate that increasing the total three-dimensional surface area can enhance FN adsorption relative to surfaces with lesser surface area. Therefore, balancing of both intercolumnar pore spacing and total surface area is an important design consideration when fabricating nanostructured surfaces to load biomolecules, such as FN. In addition, since nanocolumn density and total surface area were determined to be predominantly influencing the enhancement of FN adsorption, multiple mechanisms could affect FN adsorption to nanostructured substrates [56,57], as described next.

Protein adsorption to substrates with uniform nanotopographies, such as nanoscale diffraction gratings [58] and platinum STFs fabricated by GLAD [59], have previously demonstrated enhanced protein adsorption relative to flat substrates according to immunoassay and radiolabeling studies. While these previous studies determined values within comparable ranges of FN adsorbed mass determined by GE in the present study, the spatial distribution of FN either on top of or within nanostructured features has not been previously quantified. Modeling approaches, such as Monte Carlo and Brownian dynamics simulations, have been used to analyze the behavior of proteins adsorbing to various regions within nanostructured substrates and found that two key factors: electrostatic interactions (i.e., enhancing electrostatic surface interactions by enhancing surface area) and nanostructured steric constraints (i.e., intercolumnar void spaces), contribute to the enhancement of protein adsorption to nanostructured substrates [56,57]. Furthermore, the modeling of lysozyme adsorption to nanostructured surfaces using Brownian dynamics simulations determined that proteins initially electrostatically adsorb to convex edges of the nanostructures containing grooves (similar to STF nanocolumns), followed by protein immobilization within grooved spaces (similar to STF intercolumnar pore spaces) via surface diffusion [56]. These previous modeling studies provide additional information to explain and corroborate the results reported here, where the orientation of the nanocolumns was shown to affect the penetration of FN within the intercolumnar void space. The 
decreased FN loading within either SCTFs or ppSCTFs, relative to VCTFs, could possibly be a result of steric constraints induced by the slanted columnar morphology. These findings are further supported by the dimensional characteristics of both the protein (approx. $15 \mathrm{~nm} \times 9 \mathrm{~nm}$ [60]) and the STFs (SCTF column spacing approx. 25-30 nm and ppSCTF column spacing approx. $150 \mathrm{~nm}$ ), where the dimensions of the protein and SCTF are similar, thereby causing increased steric constraints, relative to the increased intercolumnar spacing of the ppSCTFs. Additionally, increasing the total surface area can enhance the electrostatic interactions of FN with the surface, which may explain why VCTFs enhance total FN loading relative to STF and flat surfaces as a function of increased total surface area.

Future studies of protein adsorption within nanostructured STFs will concentrate on the development of more specific computational models to determine the effects of nanostructured columns and intercolumnar void spaces on protein adsorption, loading within the three-dimensional space, and conformational characteristics. Furthermore, while previously published findings suggest that proteins adsorbed to nanostructured substrates retain their biological activity, future investigations will examine the influence of STF nanocolumns on adsorbed FN activity [61,62]. While previous investigations of protein adsorption on nanostructured substrates have demonstrated increased protein adsorption relative to flat controls, the three-dimensional distribution of biomolecules within and around nanostructured surfaces has not been experimentally investigated. Together these results indicate that GE/QCM-D can reproducibly describe the three-dimensional distribution of FN either within or on top of STFs, FN adsorption to STFs is enhanced relative to flat surfaces, and suggest that FN-loaded STFs could be used as biocompatible substrates to enhance cell-material interactions.

\subsection{Nanostructured STFs direct cell behaviors}

Following the evaluation of FN adsorption to STFs, cell viability, morphology, and proliferation was examined on both STF and STF + FN surfaces using either mouse fibroblast or mMSC cell lines. Cell adhesion on flat Ti substrates (without FN) was also found to be low relative to cell adhesion on STF substrates, which suggests that all STF substrate nanotopographies that were examined in the present study significantly contribute to enhancing cell adhesion and biocompatibility on Ti biomaterial surfaces. Previously published findings suggest that nanostructured Ti substrates possess a higher surface energy relative to flat substrates, which helps to enhance both protein adsorption and cell adhesion to nanostructured substrates relative to flat surfaces $[23,63,64]$. Additionally, nanostructured features, such as pillars or wires, have demonstrated enhanced interactions with adherent cell filopodia, which are responsible for mediating cell migration and attachment [65-67]. The biocompatibility and cell characterization results for both cell lines indicate that ppSCTF substrates consistently supported favorable cell characteristics, such as adhesion and proliferation, relative to other STF substrates, both with and without the addition of FN, though the effect of nanotopography on cell spreading was either insignificant or dependent on the cell type. These findings are supported by previously published investigations, where polymeric nanostructured substrates were found to significantly enhance cell adhesion and proliferation but reduced cell spreading [68-71]. 
Previous investigations of mouse and human fibroblast adhesion on Pt-STFs fabricated by GLAD found that decreasing nanocolumn density enhanced cell adhesion and proliferation relative to substrates with a higher nanocolumn density that were more rough [8,59]. Additionally, these studies demonstrated that increasing the nanocolumn length caused decreased cell spreading and proliferation relative to shorter features [72,73]. These findings for cells seeded on Pt-STFs agree with the results of the current investigation since ppSCTFs, with a lower nanocolumn density than both SCTFs and VCTFs (Table 1), enhanced cell adhesion and proliferation for both cell types compared to cells on SCTFs and VCTFs. However, those previous investigations of cell biocompatibility on GLAD fabricated Pt-STFs also concluded that none of the Pt-STF substrate nanotopographies enhanced cell adhesion or viability relative to the flat Pt control condition [73]. This observation is contrary to the results reported here and previously published trends, which demonstrate the enhancement of cell-material interactions on nanorough substrates relative to flat surfaces [22-24,74]. The notorious cytotoxicity of Pt [75-77] may be contributing to the disparity between these previously reported trends using Pt-STFs [73] and those reported here.

In agreement with the findings of the current investigation, the use of biocompatible materials to fabricate nanostructured features, such as titanium [23,24,74], stainless steel [22], and carbon-grafted chitosan [21], have demonstrated that substrate nanotopography and nanoroughness enhance cell-material interactions, such as cell adhesion and proliferation, relative to flat surfaces. However, since these studies evaluated cell behaviors on surfaces with disordered and irregular nanotopographical features, the present work aims to investigate protein adsorption and cell behaviors using well-defined nanostructured topographies, where FN adsorption and cell behaviors can be correlated to specific physical characteristics of STFs, such as the surface area and nanocolumn density. Additionally, the use of STFs as nanostructured biomaterials is advantageous, since these substrates present nanostructured topographies with homogenous columnar features that serve multiple purposes besides directing cell-material interactions. For example, STFs provide a customizable and scalable platform for the loading and potential release of various biomolecules, such as FN, peptides, genes, growth factors, and therapeutic drug compounds.

In addition to studying the effect of nanotopography on cell-material interactions, the current study also investigated the influences of nanostructured topographies loaded with FN on cell behaviors to determine whether cell-material interactions are primarily affected by (a) substrate nanotopography alone (as discussed in the previous paragraph), (b) the enhancement of adsorbed FN mass as a function of increase surface area afforded by STFs, or (c) a combination of both factors. The loading of FN within the nanostructured pore space of STFs demonstrated significant enhancements in mMSC cell adhesion on all substrates relative to the corresponding substrates without FN, though cell spreading was unaffected. Previously published findings suggest that while the nanocolumns provide distinct points of contact for cell adhesion, the decreased surface area available on top of the nanostructures may inhibit cell spreading $[65,66,78]$. Moreover, nanostructured substrates may prevent the unfolding of ECM proteins, such as $\mathrm{FN}$, which could prevent exposing integrin binding sites to enhance cell spreading on STF + FN substrates [61,62]. Furthermore, the addition of FN did not cause significant enhancements in mouse fibroblast cell adhesion, which indicates a cell-dependent effect of FN addition on cell adhesion, and also suggests 
that using STFs as FN loading reservoirs may not play a significant role in enhancing cellmaterial interactions compared to the effects of the STF nanotopography.

The comparison of cell behaviors within the group of STF + FN substrates provide insights into the influences of the degree of FN loaded within the columns on cell behaviors by comparing the results between the protein loading and cell studies. For example, the previously described FN adsorption results demonstrated that VCTFs significantly enhanced FN protein adsorption to the top of as well as within the STF columnar spaces relative to other STFs and flat control conditions. However, the ability of VCTFs to immobilize the most FN did not directly translate to enhanced cell adhesion, morphology, and proliferation characteristics. Instead, ppSCTFs with less adsorbed FN than VCTFs (Fig. 2C), supported improved cell-material interactions, as indicated by the cell adhesion and proliferation results (Figs. 4 and 5). These findings suggest that the STF substrate nanotopography primarily influences the enhancement of cell-material interactions (particularly cell adhesion and proliferation), rather than the increased amount of FN on and within the STFs. These findings are speculated to be attributed to the cells' limited access to FN protein within the STF intercolumnar void space and possibly limited biological activity of FN adsorbed to nanostructured features. While STFs (VCTFs in particular) may adsorb more FN than flat substrates, most of the FN adsorbed to STFs might not affect cell-material interactions due to the limited accessibility of FN located within the intercolumnar space of STFs to cells adhered on top of the nanocolumns. In contrast, FN significantly enhanced cell adhesion on flat substrates, since all of the FN adsorbed to the flat surface was readily available to cells for enhancing cell adhesion and spreading. These trends indicate that STFs act as biomolecule reservoirs that can efficiently load FN, but that this enhanced amount of FN adsorbed within STFs relative to flat surfaces plays a minor role in enhancing cellmaterial interactions, which are primarily affected by substrate nanotopography.

\section{Conclusions}

Combinatorial GE/QCM-D was used to dynamically measure the three-dimensional spatial distribution of FN within STFs and protein adsorption was determined to be enhanced on STFs relative to flat substrates due to the STF nanotopography and loading of FN within STF intercolumnar spaces. The examination of FN loading within STFs determined that two STF substrate properties affect the loading of FN within STFs. First, VCTF substrates, with vertically oriented nanocolumns and high nanocolumn density, were found to significantly enhance FN adsorption as a function of the increased surface area relative to SCTFs, ppSCTFs, and flat surfaces. Second, ppSCTF substrates, with slanted nanocolumns and low nanocolumn density, were found to enhance total FN adsorption relative to SCTFs and flat surfaces, presumably due to the increased ambient pore space for FN to physically penetrate within the three-dimensional volume of the STF. The biocompatibility of NIH/3T3 mouse fibroblast and mMSC lines was also investigated on various Ti-STF substrates, both with and without adsorbed FN. Cells cultured on different STF nanotopographies demonstrated that the contributions of STF nanostructured features, such as nanocolumn orientation and spacing, enhance cell characteristics, such as cell adhesion, viability, and proliferation relative to flat surfaces. The overall findings of the cell biocompatibility and 
morphology investigations determined that ppSCTF substrates, both with and without pre-adsorbed FN, significantly enhance cell-material interactions relative to the SCTF, VCTF, and flat control substrates for both cell types evaluated. In addition, comparisons of trends between the total amount of FN adsorbed to STFs and cell-material responses between substrates containing FN indicate that the substrate nanotopography, not the enhancement of adsorbed FN within STFs, predominantly contributes to the enhancement of cell-material interactions on nanostructured STF substrates. These findings demonstrate that nanostructured Ti-STF substrates are biocompatible substrates that enhance cell-surface interactions and the influences of STF nanotopography on cell-material interactions can be applied to the design of nanostructured substrates for the loading of biomolecules and culture of cells for biomaterial, tissue engineering, and diagnostic applications.

Disclosure - The authors have no conflict of interest to declare.

Acknowledgments - Support for this research was provided in part by funds from the National Science Foundation (CAREER to AKP, CBET-1254415), Center for Nanohybrid Functional Materials (NSF EPS-1004094), American Heart Association (\#10SDG2640217), the University of Nebraska Foundation (Layman Funds), the J. A. Woollam Company, and USDA CSREES-Nebraska (NEB-21146).

\section{References}

1. Sweetman MJ, Ronci M, Ghaemi SR, Craig JE, Voelcker NH. Porous silicon films micropatterned with bioelements as supports for mammalian cells. Adv Funct Mater 2012;22:1158-66.

2. Schweikl H, Muller R, Englert C, Hiller KA, Kujat R, Nerlich M, et al. Proliferation of osteoblasts and fibroblasts on model surfaces of varying roughness and surface chemistry. J Mater Sci Mater Med 2007;18:1895-905.

3. Vagaska B, Bacakova L, Filova E, Balik K. Osteogenic cells on bio-inspired materials for bone tissue engineering. Physiol Res 2010;59:309-22.

4. Reich U, Fadeeva E, Warnecke A, Paasche G, Muller P, Chichkov B, et al. Directing neuronal cell growth on implant material surfaces by microstructuring. J Biomed Mater Res Part B Appl Biomater 2012;100B:940-7.

5. Lee BH, Li B, Guelcher SA. Gel microstructure regulates proliferation and differentiation of MC3T3-E1 cells encapsulated in alginate beads. Acta Biomater 2012;8:1693-702.

6. Bazaka K, Crawford RJ, Ivanova EP. Do bacteria differentiate between degrees of nanoscale surface roughness? Biotechnol J 2011;6:1103-14.

7. Venkatsurya PKC, Girase B, Misra RDK, Pesacreta TC, Somani MC, Karjalainen LP. The interplay between osteoblast functions and the degree of nanoscale roughness induced by grain boundary grooving of nanograined materials. Mater Sci Eng C - Mater Biol Appl 2012;32:330-40.

8. Pennisi CP, Dolatshahi-Pirouz A, Foss M, Chevallier J, Fink T, Zachar V, et al. Nanoscale topography reduces fibroblast growth, focal adhesion size and migration-related gene expression on platinum surfaces. Colloids Surf B 2011;85:189-97.

9. Brunetti V, Maiorano G, Rizzello L, Sorce B, Sabella S, Cingolani R, et al. Neurons sense nanoscale roughness with nanometer sensitivity. Proc Natl Acad Sci USA 2010;107:6264-9. 
10. Webster TJ, Ergun C, Doremus RH, Siegel RW, Bizios R. Specific proteins mediate enhanced osteoblast adhesion on nanophase ceramics. J Biomed Mater Res 2000;51:475-83.

11. Lipski AM, Pino CJ, Haselton FR, Chen IW, Shastri VP. The effect of silica nanoparticle-modified surfaces on cell morphology, cytoskeletal organization and function. Biomaterials 2008;29:3836-46.

12. Pareta RA, Reising AB, Miller T, Storey D, Webster TJ. Increased endothelial cell adhesion on plasma modified nanostructured polymeric and metallic surfaces for vascular stent applications. Biotechnol Bioeng 2009;103:459-71.

13. Shen Y, Wang GX, Chen L, Li H, Yu P, Bai MJ, et al. Investigation of surface endothelialization on biomedical nitinol (NiTi) alloy: effects of surface micropatterning combined with plasma nanocoatings. Acta Biomater 2009;5:3593-604.

14. Woo KM, Chen VJ, Ma PX. Nano-fibrous scaffolding architecture selectively enhances protein adsorption contributing to cell attachment. J Biomed Mater Res, Part A 2003;67A:531-7.

15. Zhang J, Fu DL, Chan-Park MB, Li LJ, Chen P. Nanotopographic carbon nanotube thin-film substrate freezes lateral motion of secretory vesicles. Adv Mater 2009;21:790.

16. Ryu S, Kim BS. Culture of neural cells and stem cells on graphene. Tissue Eng Regener Med 2013;10:39-46.

17. Gladwin KM, Whitby RLD, Mikhalovsky SV, Tomlins P, Adu J. In vitro biocompatibility of multiwalled carbon nanotubes with sensory neurons. Adv Healthcare Mater 2013;2:728-35.

18. Akasaka T, Yokoyama A, Matsuoka M, Hashimoto T, Watari F. Thin films of single-walled carbon nanotubes promote human osteoblastic cells (Saos-2) proliferation in low serum concentrations. Mater Sci Eng C - Mater Biol Appl 2010;30:391-9.

19. Emohare O, Rushton N. Immobilized MWCNT support osteogenic cell culture. J Mater Sci Mater Med 2013;24:1543-50.

20. Li JA, Yang P, Zhang K, Ren HL, Huang N. Preparation of $\mathrm{SiO}_{2} / \mathrm{TiO}_{2}$ and $\mathrm{TiO}_{2} / \mathrm{TiO}_{2}$ micropattern and their effects on platelet adhesion and endothelial cell regulation. Nucl Instr Methods Phys Res B 2013;307:575-9.

21. Depan D, Misra RDK. The interplay between nanostructured carbon-grafted chitosan scaffolds and protein adsorption on the cellular response of osteoblasts: structure-function property relationship. Acta Biomater 2013;9:6084-94.

22. Misra RDK, Nune C, Pesacreta TC, Somani MC, Karjalainen LP. Interplay between grain structure and protein adsorption on functional response of osteoblasts: ultrafine-grained versus coarse-grained substrates. J Biomed Mater Res, Part A 2013;101A:1-12.

23. Rivera-Chacon DM, Alvarado-Velez M, Acevedo-Morantes CY, Singh SP, Gultepe E, Nagesha D, et al. Fibronectin and vitronectin promote human fetal osteoblast cell attachment and proliferation on nanoporous titanium surfaces. J Biomed Nanotechnol 2013;9:1092-7.

24. Novin M, Faghihi S. Mouse bone marrow-derived mesenchymal stem cell response to nanostructured titanium substrates produced by high-pressure torsion. Surf Interface Anal 2013;45: 619-27.

25. He Y, Zhao Y. Advanced multi-component nanostructures designed by dynamic shadowing growth. Nanoscale 2011;3:2361-75.

26. Lisfi A, Lodder JC. Magnetic domains in Co thin films obliquely sputtered on a polymer substrate. Phys Rev B 2001;63.

27. Elias AL, Harris KD, Bastiaansen CWM, Broer DJ, Brett MJ. Large-area microfabrication of threedimensional, helical polymer structures. J Micromech Microeng 2005;15:49-54. 
28. Schmidt D, Kjerstad AC, Hofmann T, Skomski R, Schubert E, Schubert M. Optical, structural, and magnetic properties of cobalt nanostructure thin films. J Appl Phys 2009;105.

29. Steele JJ, Brett MJ. Nanostructure engineering in porous columnar thin films: recent advances. J Mater Sci - Mater Electron 2007;18:367-79.

30. Robbie K, Brett MJ, Lakhtakia A. Chiral sculptured thin films. Nature 1996;384:616.

31. Zhao YP, Ye DX, Wang GC, Lu TM. Designing nanostructures by glancing angle deposition. In: Lakhtakia AMS, editor. Nanotubes and Nanowires 2003. p. 59-73.

32. Liang D, Schmidt D, Wang H, Schubert E, Schubert M. Generalized ellipsometry effective medium approximation analysis approach for the porous slanted columnar thin films infiltrated with polymer. Appl Phys Lett 2013;103.

33. Schmidt D, Müller C, Hofmann T, Inganäs O, Arwin H, Schubert E, et al. Optical properties of hybrid titanium chevron sculptured thin films coated with a semiconducting polymer. Thin Solid Films 2011;519:2645-9.

34. Kasputis T, Koenig M, Schmidt D, Sekora D, Rodenhausen KB, Eichhorn KJ, et al. Slanted columnar thin films prepared by glancing angle deposition functionalized with polyacrylic acid polymer brushes. J Phys Chem C 2013;117:13971.

35. Koenig M, Kasputis T, Schmidt D, Rodenhausen KB, Eichhorn KJ, Pannier AK, et al. Combined QCM-D/GE as a tool to characterize stimuli-responsive swelling of and protein adsorption on polymer brushes grafted onto 3D-nanostructures. Anal Bioanal Chem 2014;406:7233-42.

36. Rodenhausen KB, Schmidt D, Kasputis T, Pannier AK, Schubert E, Schubert M. Generalized ellipsometry in-situ quantification of organic adsorbate attachment within slanted columnar thin films. Opt Express 2012;20: 5419-28.

37. Thomas M, Worfolk BJ, Rider DA, Taschuk MT, Buriak JM, Brett MJ. C(60) Fullerene nanocolumns-polythiophene heterojunctions for inverted organic photovoltaic cells. ACS Appl Mater Interfaces 2011;3:1887-94.

38. Gerein NJ, Fleischauer MD, Brett MJ. Effect of TiO(2) film porosity and thermal processing on $\mathrm{TiO}(2)-\mathrm{P} 3 \mathrm{HT}$ hybrid materials and photovoltaic device performance. Sol Energy Mater Sol Cells 2010;94:2343-50.

39. Rider DA, Tucker RT, Worfolk BJ, Krause KM, Lalany A, Brett MJ, et al. Indium tin oxide nanopillar electrodes in polymer/fullerene solar cells. Nanotechnology 2011;22.

40. Harris KD, Brett MJ, Smy TJ, Backhouse C. Microchannel surface area enhancement using porous thin films. J Electrochem Soc 2000;147:2002-6.

41. Joos U, Biskup T, Ernst O, Westphal I, Gherasim C, Schmidt R, et al. Investigation of cell adhesion to structured surfaces using total internal reflection fluorescence and confocal laser scanning microscopy. Eur J Cell Biol 2006;85:225-8.

42. Schmidt D, Schubert E, Schubert M. Generalized ellipsometry determination of non-reciprocity in chiral silicon sculptured thin films. Phys Status Solid A - Appl Mater Sci 2008;205:748-51.

43. Schmidt D, Schubert E, Schubert M. Optical properties of cobalt slanted columnar thin films passivated by atomic layer deposition. Appl Phys Lett 2012;100.

44. Rodenhausen KB, Duensing BA, Kasputis T, Pannier AK, Hofmann T, Schubert M, et al. In-situ monitoring of alkanethiol self-assembled monolayer chemisorption with combined spectroscopic ellipsometry and quartz crystal microbalance techniques. Thin Solid Films 2011;519:2817-20.

45. Bittrich E, Rodenhausen KB, Eichhorn KJ, Hofmann T, Schubert M, Stamm M, et al. Protein adsorption on and swelling of polyelectrolyte brushes: a simultaneous ellipsometry-quartz crystal microbalance study. Biointerphases 2010;5:1-9. 
46. Rodenhausen KB, Kasputis T, Pannier AK, Gerasimov JY, Lai RY, Solinsky M, et al. Combined optical and acoustical method for determination of thickness and porosity of transparent organic layers below the ultra-thin film limit. Rev Sci Instrum 2011;82:103111.

47. Dolatshahi-Pirouz A, Jensen THL, Kolind K, Bunger C, Kassem M, Foss M, et al. Cell shape and spreading of stromal (mesenchymal) stem cells cultured on fibronectin coated gold and hydroxyapatite surfaces. Colloids Surf B 2011;84: 18-25.

48. Liu LY, Ratner BD, Sage EH, Jiang SY. Endothelial cell migration on surface-density gradients of fibronectin, VEGF, or both proteins. Langmuir 2007;23:11168-73.

49. Garcia AJ, Keselowsky BG, Gersbach CA, Cutler SM, Gallant ND, Frazier AB, et al. Engineered surfaces to control fibronectin adsorption and modulate integrin binding. Mol Biol Cell 2000; 11:393A-4A.

50. Pompe T, Keller K, Mitdank C, Werner C. Fibronectin fibril pattern displays the force balance of cell-matrix adhesion. Europ Biophys J Biophys Lett 2005;34: 1049-56.

51. Lan MA, Gersbach CA, Michael KE, Keselowsky BG, Garcia AJ. Myoblast proliferation and differentiation on fibronectin-coated self assembled monolayers presenting different surface chemistries. Biomaterials 2005;26: 4523-31.

52. Pompe T, Renner L, Werner C. Nanoscale features of fibronectin fibrillogenesis depend on proteinsubstrate interaction and cytoskeleton structure. Biophys J 2005;88:527-34.

53. Keselowsky BG, Collard DM, Garcia AJ. Surface chemistry modulates fibronectin conformation and directs integrin binding and specificity to control cell adhesion. J Biomed Mater Res, Part A 2003;66A:247-59.

54. Ratner BD, Castner DG, Horbett TA, Lenk TJ, Lewis KB, Rapoza RJ. Biomolecules and surfaces. J Vac Sci Technol A 1990;8:2306-17.

55. MacDonald DE, Markovic B, Allen M, Somasundaran P, Boskey AL. Surface analysis of human plasma fibronectin adsorbed to commercially pure titanium materials. J Biomed Mater Res 1998; 41:120-30.

56. Elter $P$, Lange R, Beck U. Electrostatic and dispersion interactions during protein adsorption on topographic nanostructures. Langmuir 2011;27:8767-75.

57. Sabirianov RF, Rubinstein A, Namavar F. Enhanced initial protein adsorption on engineered nanostructured cubic zirconia. Phys Chem Phys 2011;13: 6597-609.

58. Salakhutdinov I, VandeVord P, Palyvoda O, Matthew H, Tatagiri G, Handa H, et al. Fibronectin adsorption to nanopatterned silicon surfaces. J Nanomater 2008.

59. Dolatshahi-Pirouz A, Pennisi CP, Skeldal S, Foss M, Chevallier J, Zachar V, et al. The influence of glancing angle deposited nano-rough platinum surfaces on the adsorption of fibrinogen and the proliferation of primary human fibroblasts. Nanotechnology 2009;20.

60. Koteliansky VE, Glukhova MA, Bejanian MV, Smirnov VN, Filimonov VV, Zalite OM, et al. A study of the structure of fibronectin. Eur J Biochem 1981;119:619-24.

61. Shi HQ, Tsai WB, Garrison MD, Ferrari S, Ratner BD. Template-imprinted nanostructured surfaces for protein recognition. Nature 1999;398:593-7.

62. Dolatshahi-Pirouz A, Rechendorff K, Hovgaard MB, Foss M, Chevallier J, Besenbacher F. Bovine serum albumin adsorption on nano-rough platinum surfaces studied by QCM-D. Colloid Surf B 2008;66:53-9.

63. Zhao G, Schwartz Z, Wieland M, Rupp F, Geis-Gerstorfer J, Cochran DL, et al. High surface energy enhances cell response to titanium substrate microstructure. J Biomed Mater Res, Part A 2005;74A:49-58. 
64. Khang D, Lu J, Yao C, Haberstroh KM, Webster TJ. The role of nanometer and sub-micron surface features on vascular and bone cell adhesion on titanium. Biomaterials 2008;29:970-83.

65. Teo BKK, Goh SH, Kustandi TS, Loh WW, Low HY, Yim EKF. The effect of micro and nanotopography on endocytosis in drug and gene delivery systems. Biomaterials 2011;32:9866-75.

66. Anselme K, Davidson P, Popa AM, Giazzon M, Liley M, Ploux L. The interaction of cells and bacteria with surfaces structured at the nanometre scale. Acta Biomater 2010;6:3824-46.

67. Albuschies J, Vogel V. The role of filopodia in the recognition of nanotopographies. Sci Rep 2013;3.

68. Thakar RG, Cheng Q, Patel S, Chu J, Nasir M, Liepmann D, et al. Cell-shape regulation of smooth muscle cell proliferation. Biophys J 2009;96: 3423-32.

69. Tajima S, Chu JSF, Li S, Komvopoulos K. Differential regulation of endothelial cell adhesion, spreading, and cytoskeleton on low-density polyethylene by nanotopography and surface chemistry modification induced by argon plasma treatment. J Biomed Mater Res, Part A 2008;84A:828-36.

70. Cheng Q, Li S, Komvopoulos K. Plasma-assisted surface chemical patterning for single-cell culture. Biomaterials 2009;30:4203-10.

71. Cheng Q, Lee BLP, Komvopoulos K, Yan ZQ, Li S. Plasma surface chemical treatment of electrospun poly(L-lactide) microfibrous scaffolds for enhanced cell adhesion, growth, and infiltration. Tissue Eng Part A 2013;19:1188-98.

72. Heydarkhan-Hagvall S, Chof CH, Dunn J, Heydarkhan S, Schenke-Layland K, Maclellan WR, et al. Influence of systematically varied nano-scale topography on cell morphology and adhesion. Cell Commun Adhes 2007;14:181-94.

73. Pennisi CP, Sevcencu C, Dolatshahi-Pirouz A, Foss M, Hansen JL, Larsen AN, et al. Responses of fibroblasts and glial cells to nanostructured platinum surfaces. Nanotechnology 2009;20.

74. Lai M, Cai K, Hu Y, Yang X, Liu Q. Regulation of the behaviors of mesenchymal stem cells by surface nanostructured titanium. Colloid Surf B 2012;97:211-20.

75. Lovejoy KS, Serova M, Bieche I, Emami S, D’Incalci M, Broggini M, et al. Spectrum of cellular responses to pyriplatin, a monofunctional cationic antineoplastic platinum(II) compound, in human cancer cells. Mol Cancer Ther 2011;10:1709-19.

76. Yonezawa A, Inui K. Organic cation transporter OCT/SLC22A and H+/organic cation antiporter MATE/SLC47A are key molecules for nephrotoxicity of platinum agents. Biochem Pharmacol 2011;81:563-8.

77. More SS, Akil O, Ianculescu AG, Geier EG, Lustig LR, Giacomini KM. Role of the copper transporter, CTR1, in platinum-induced ototoxicity. J Neurosci 2010;30:9500-9.

78. Lopez-Bosque MJ, Tejeda-Montes E, Cazorla M, Linacero J, Atienza Y, Smith KH, et al. Fabrication of hierarchical micro-nanotopographies for cell attachment studies. Nanotechnology 2013; 24. 


\section{Supplemental Methods}

\section{S1.1 Electron Beam Glancing Angle Deposition}

For slanted columnar thin film (SCTF, Scheme 1) depositions, Ti was evaporated with a deposition thickness of $2200 \AA$ and an $85^{\circ}$ vapor flux angle. Vertical columnar thin films (VCTFs, Scheme 1) were deposited with a deposition thickness of $2400 \AA, 86^{\circ}$ vapor flux, and 3 rpm counterclockwise substrate rotation. SCTFs with wider column spacing, referred to as prepatterned SCTFs (ppSCTFs, Scheme 1) were prepared by depositing SCTFs on a prenucleated Ti adhesion layer. The vapor flux angle, substrate rotation, and deposition times were modulated to fabricate STFs with different column slanting angles and spacing, while keeping a $100 \mathrm{~nm}$ constant film thickness. The Ti nucleation layer was deposited with a $100 \AA$ thickness and $0^{\circ}$ vapor flux, followed immediately by a $1500 \AA$ deposition of $\mathrm{Ti}$ at a $85^{\circ}$ vapor flux. To compare protein adsorption against a flat control surface a flat titanium thin film (Scheme 1) was deposited with a deposition thickness of $1000 \AA, 0^{\circ}$ vapor flux, and $2 \mathrm{rpm} \mathrm{CCW}$ substrate rotation. Scanning electron microscopy (SEM) was used to obtain cross-section images of STFs both with and without adsorbed FN. Freshly deposited samples were cut in half using a razor blade to expose STF crosssections. One half of each STF sample was immersed in $10 \mu \mathrm{g} / \mathrm{mL}$ FN solution followed by a $1 \mathrm{X}$ PBS rinse, while the other respective halves were not treated with FN. Then, all samples were lyophilized overnight using a FreeZone Plus lyophilizer (Labconco, Kansas City, MO), immediately followed by mounting cross sections on SEM stages and gold sputtering using a 108 auto sputter coater (Cressington, Watford, UK). Cross-sections were imaged using a Nova NanoSEM (FEI, Hillsboro, Oregon) with a $2 \mathrm{kV}$ electron 
acceleration, beam spot of 2.5, working distance of $2.5 \mathrm{~mm}$, and magnifications of either $150 \mathrm{k}$ or $200 \mathrm{k}$.

\section{S1.2 Generalized and Spectroscopic Ellipsometry Data Modeling}

GE was used to characterize the fabrication of the GLAD STF as well as the in situ adsorption characteristics of proteins. Spectroscopic data was acquired at multiple discrete wavelengths between 400 and $900 \mathrm{~nm}$, four angles of incidence (AOI: $45^{\circ}, 55^{\circ}$, $65^{\circ}$, and $75^{\circ}$ ), and $0-360^{\circ}$ rotation (measured every $6^{\circ}$ ) in the polar azimuth plane, measured in standard ambient temperature and pressure conditions. Spectral Muellermatrix data obtained by GE was modeled and analyzed with WVASE32 software (J. A. Woollam Co.) using an anisotropic Bruggeman effective medium approximation (ABEMA) approach, which allows for the determination of geometrical thin film parameters as well as fractions of multiple constituents [32-36]. The optical model considers the underlying gold substrate and an AB-EMA layer which consists of a biaxial $\mathrm{Ti} / \mathrm{TiO}_{2} \mathrm{STF}$ constituent, an ambient void fraction (either air or buffer solution), and the protein constituent modeled as a Cauchy dispersion layer of organic inclusions within the biaxial component (Scheme 2, $\mathrm{GE}_{\mathrm{EMA}} ; \mathrm{n}=1.5, \mathrm{k}=0$ ) [36]. In addition, a Cauchy dispersion layer was added on top of the AB-EMA layer to describe FN adsorption to the top of STF substrates (Scheme 2, GE TOP). Flat control substrates also considered the underlying gold substrate, included an isotropic bulk $\mathrm{Ti} / \mathrm{TiO}_{2}$ layer, and protein adsorption to the top of the isotropic layer was described using the Cauchy dispersion parameter (GETOP). Detailed accounts regarding the theory, assumptions, and previous investigations using similar modeling approaches can be found in previous publications [32-36]. 


\section{S1.3 Quartz Crystal Microbalance with Dissipation Data Modeling}

QCM is an acoustical measurement technique that operates on the principles of piezoelectric nanogravimmetry allowing for the in situ acquisition of thin film and molecular adsorbate physical parameters such as thickness, surface coverage density, and viscoelasticity. For QCM configurations with the capability to detect frequency dissipation changes (i.e., QCM-D), shear vibration waves are triggered by the QCM-D unit in a pulse mode. Changes in frequency are indicative of surface events such as molecular adsorption, desorption, or rearrangement. A frequency decrease indicates adsorbate attachment to the surface and vice versa. Since this configuration operates in pulse mode, the frequency dissipation of each vibrational pulse can be detected. The measurement of frequency dissipation change $(\Delta \mathrm{D})$, allows for the evaluation of adsorbate viscoelasticity, which in previous publications with regard to protein adsorption, has been described as a rigid layer that can be modeled by the Sauerbrey relation [36].

\section{S1.4 Cell Viability and Proliferation Assays}

Cells stained for the Live/Dead assay were imaged with a Leica DMI 3000B fluorescence microscope (Leica Microsystems CMS GmbH, Wetzlar, Germany) and three images per well of three replicate wells were acquired using a 10x objective (9 images total per condition). Images were subsequently analyzed using NIH ImageJ 64 to quantify cell count, average cell spreading, and to process Live/Dead image overlays. The adhered cell count was determined by manually counting the number of live cells (stained Calcein AM) per image using the cell counter tool in NIH ImageJ 64. Average cell spreading was 
determined using NIH ImageJ 64 to measure the surface area occupied by adhered cells, reported in $\mu \mathrm{m}^{2}$ and normalized to the previously quantified cell count of the same image to obtain and average cell area per cell. For both Live/Dead staining and WST-1 assays, wafers seeded with cells were moved to new wells prior to staining or WST-1 assay to ensure that only cells on substrates were being assayed and normalized to the respective sample surface area. WST-1 assays were quantified using an Epoch microplate spectrophotometer (BioTek Instruments, Inc., Winooski, Vermont) and measuring the absorbance at $\lambda=430 \mathrm{~nm}$, with all absorbance (optical density - O.D.) readings normalized to the corresponding surface area for each substrate. 


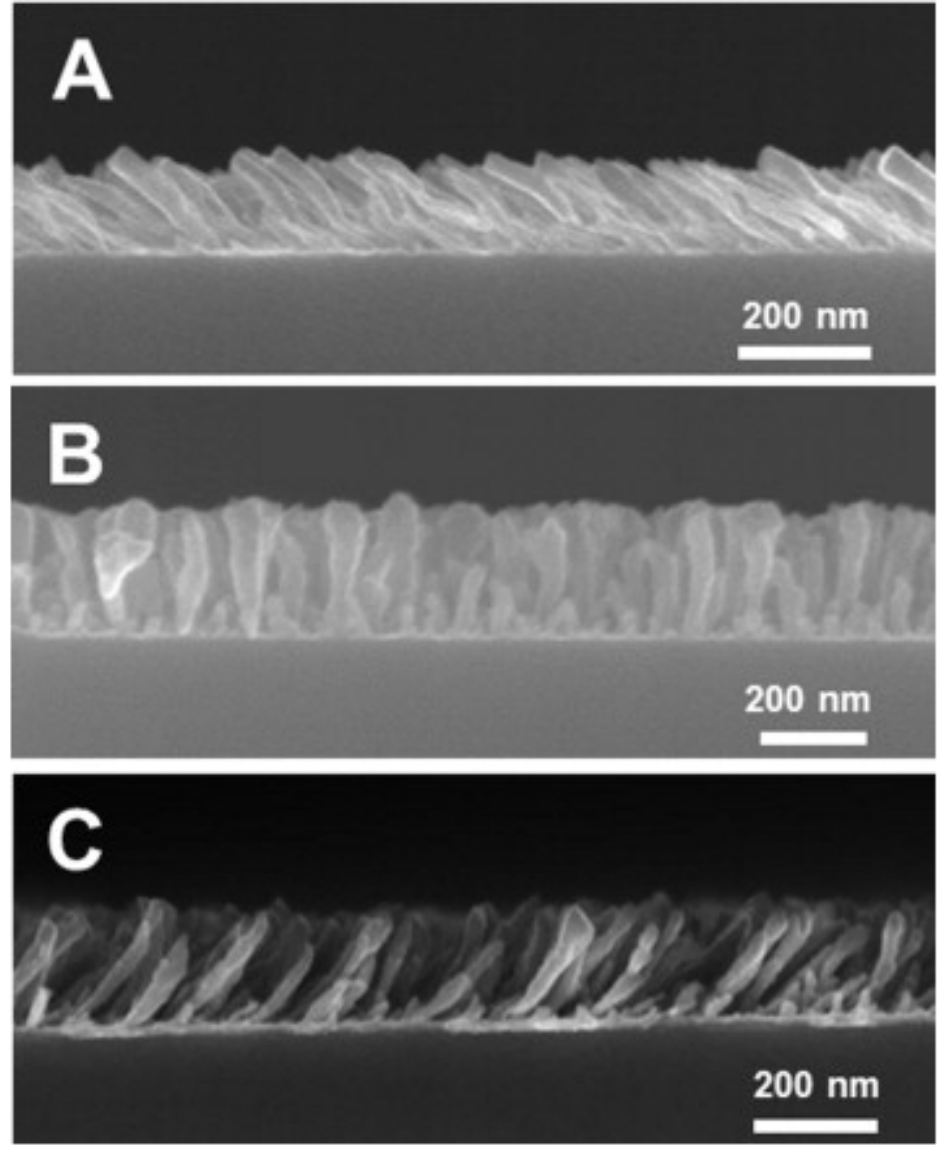

Supplementary Figure S1. Scanning electron microscopy images of SCTF (A), VCTF (B), and ppSCTF (C) substrates as-deposited, imaged immediately following GLAD deposition. Scale bars included on all images represent a length of $200 \mathrm{~nm}$. 

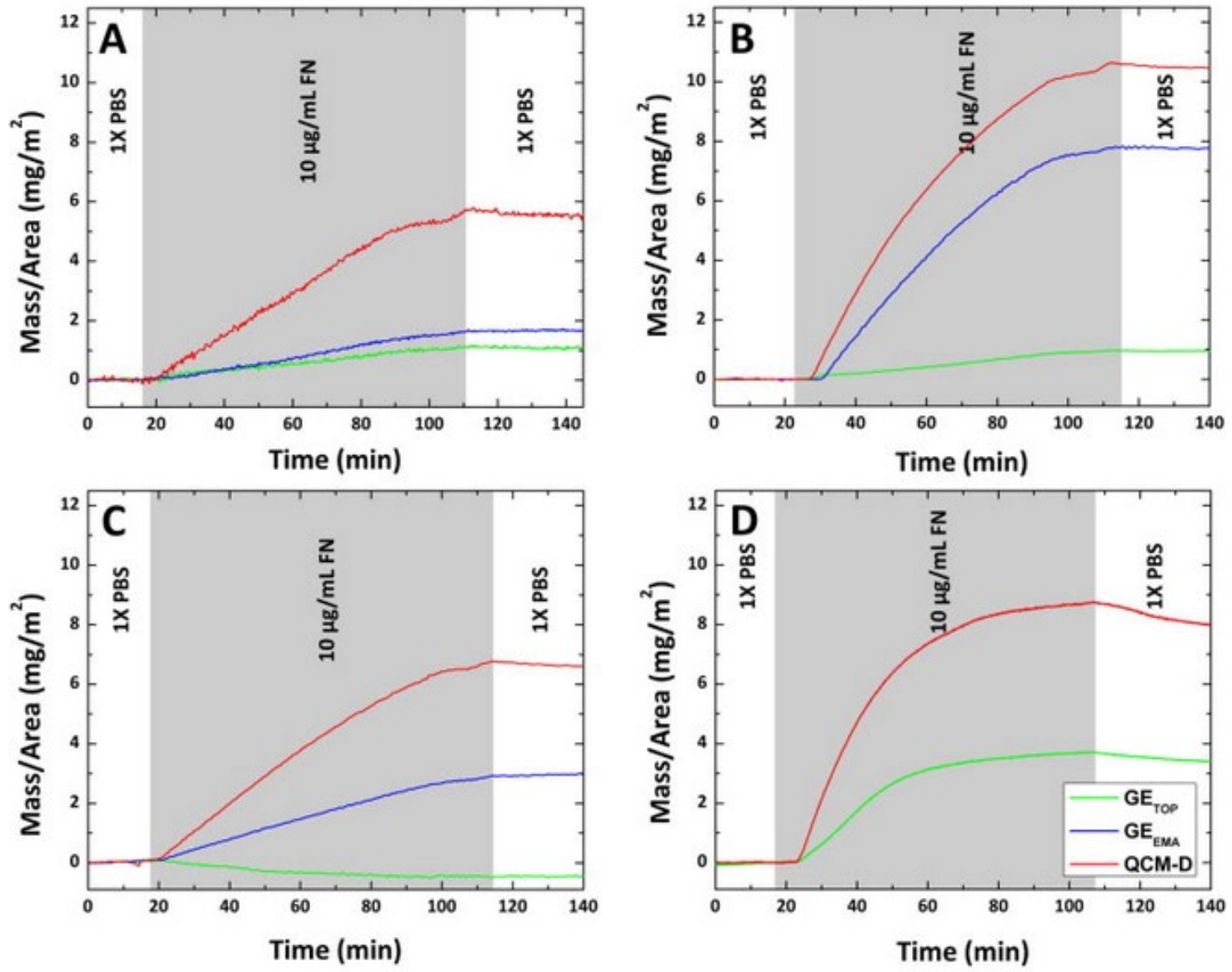

Supplementary Figure S2. Representative modeled combinatorial in situ GE/QCM-D measurements comparing FN adsorption to $\operatorname{SCTF}(\mathrm{A}), \operatorname{VCTF}(\mathrm{B}), \operatorname{ppSCTF}(\mathrm{C})$, and flat (D) substrates. The green line represents protein adsorption immobilized on top of substrates detected by GE (Cauchy top-layer modeled parameter), the blue line represents the amount of protein immobilized within STF intercolumnar pore space detected by GE (EMA modeled parameter), and the red line represents the amount of adsorbed protein and coupled solvent detected by QCM-D (Sauerbrey calculated parameter). 